\title{
BioOne enesencen

\section{Comparative Morphology of the Hominin and African Ape Hyoid Bone, a Possible Marker of the Evolution of Speech}

Author(s): James Steele, Margaret Clegg, and Sandra Martelli

Source: Human Biology, 85(5):639-672. 2013.

Published By: Wayne State University Press

DOI: http://dx.doi.org/10.3378/027.085.0501

URL: http://www.bioone.org/doi/full/10.3378/027.085.0501

BioOne (www.bioone.org) is a nonprofit, online aggregation of core research in the biological, ecological, and environmental sciences. BioOne provides a sustainable online platform for over 170 journals and books published by nonprofit societies, associations, museums, institutions, and presses.

Your use of this PDF, the BioOne Web site, and all posted and associated content indicates your acceptance of BioOne's Terms of Use, available at www.bioone.org/page/terms_of_use.

Usage of BioOne content is strictly limited to personal, educational, and non-commercial use. Commercial inquiries or rights and permissions requests should be directed to the individual publisher as copyright holder. 


\title{
Comparative Morphology of the Hominin and African Ape Hyoid Bone, a Possible Marker of the Evolution of Speech
}

JAMES STEELE, ${ }^{*}$ MARGARET CLEGG, ${ }^{2}$ AND SANDRA MARTELLI ${ }^{1}$

\begin{abstract}
This study examines the morphology of the hyoid in three closely related species, Homo sapiens, Pan troglodytes, and Gorilla gorilla. Differences and similarities between the hyoids of these species are characterized and used to interpret the morphology and affinities of the Dikika A.afarensis, Kebara 2 Neanderthal, and other fossil hominin hyoid bones.

Humans and African apes are found to have distinct hyoid morphologies. In humans the maximum width across the distal tips of the articulated greater horns is usually slightly greater than the maximum length (distal greater horn tip to most anterior point of the hyoid body in the midline). A different pattern is usually found in the African ape hyoids, which have much greater maximum lengths. In humans, the hyoid body is also much more anteroposteriorly shallow in proportion to its height and width, and this is true for all age classes.
\end{abstract}

The Dikika australopithecine hyoid body proportions are chimpanzeelike. A discriminant function analysis, using a larger subadult sample from the three extant species than that reported by Alemseged et al. (2006), confirms this finding. The Kebara hyoid dimensions (body alone, and articulated body and greater horns) are almost all within the observed range for human hyoids. Discriminant functions clearly distinguish human from African ape hyoids and classify the Kebara 2 hyoid as human (confirming the finding of Arensburg et al. 1989).

Our virtual dissection of a chimpanzee air sac system shows its subhyoid extension into the dorsal hyoid body. Following Alemseged et al. (2006), the expanded bulla characteristic of the African ape and australopithecine hyoid body is therefore interpreted as reflecting the presence of such a laryngeal air sac extension. Its absence in the human, Neanderthal, and $H$. heidelbergensis (Atapuerca SH) hyoids implicates the loss of the laryngeal air sacs as a derived

${ }^{1}$ AHRC Centre for the Evolution of Cultural Diversity, Institute of Archaeology, University College London, London, United Kingdom.

${ }^{2}$ Department of Palaeontology, Natural History Museum, London, United Kingdom.

*Correspondence to: James Steele, AHRC Centre for the Evolution of Cultural Diversity, Institute of Archaeology, University College London, 31-34 Gordon Square, London WC1H 0PY, UK. E-mail: j.steele@ucl.ac.uk.

Human Biology, October 2013, v. 85, no. 5, pp. 639-xx.

Copyright (C) 2014 Wayne State University Press, Detroit, Michigan 48201-1309 ORIGINS.

KEY WORDS: HYOID, VOCAL TRACT, AIR SAC, DIKIKA, NEANDERTHAL, LANGUAGE 
Neanderthal and modern human trait, which evolved no later than the middle Pleistocene. If, as has been argued by de Boer (2012), the loss of the air sac helped to enhance perceptual discrimination of speech sounds, then this derived hyoid morphology can be added to the list of fossil markers of the capacity for speech.

This study examines the morphology of the hyoid bone, its relationship with the air sac (where present), and its scaling with skull and mandible dimensions in three extant hominoid species, Homo sapiens, Pan troglodytes, and Gorilla gorilla. Results from those tests are then used to inform interpretation of the A. afarensis hyoid from Dikika, Ethiopia (Alemseged et al. 2006), the Neanderthal hyoid from Kebara Cave, Israel (Arensburg et al. 1989), and other fossil hyoids from middle Pleistocene hominins and to assess their implications for the evolution of hominin vocal tracts and the capacity for speech.

Hyoid Anatomy in Humans and Great Apes. In adult primates, humans included, the hyoid presents approximately as a horseshoe-shaped bone, located in the midsagittal plane of the neck, just inferior to the mandible and above the thyroid cartilage. The bones forming the adult primate hyoid are the unpaired body (basihyoid), the paired greater horns (thyrohyals), and the paired lesser horns (ceratohyals) (Liem et al. 2001; see also Senecail 1979). Developmentally, the hyoid bone is part of the pharynx, with the inferior half of the hyoid body and the greater horns originating from the third pharyngeal arch and the superior half of the hyoid body and the lesser horns arising from the second pharyngeal arch (Meikle 2002). The mammalian hyoid is usually suspended from the temporal bone via a series of small bone elements (e.g., the epihyal, stylohyal, and tympanohyal, connecting to the lesser horns). However, in primates among some other mammalian groups, this series of bones is fused to the temporal bone in the form of a styloid process, and the hyoid's lesser horns connect to it via the stylohyoid muscle and ligament (Liem et al. 2001). Further attachments of the hyoid are to the oral cavity floor by the suprahyoid musculature-especially geniohyoid and mylohyoid - and to the thyroid cartilage by the thyrohyoid membrane and the infrahyoid musculature. The hyoid forms the osseous base of the tongue and plays an important role in its motion. It also lifts the larynx and thus plays a crucial role in swallowing (Dodds et al. 1990).

In humans, the hyoid body is flat and bar shaped (see Figure 1). The greater horns have a tendency to fuse with the body after the age of 40 (bilaterally or unilaterally), but in many individuals this is not the case even in old age (Miller et al. 1998; O'Halloran and Lundy 1987). The human hyoid is positioned below the inferior margin of the mandibular body, approximately at the level of C3 to C4, and thus lies clearly below the tongue root.

In great apes, on the other hand, the hyoid is placed superior to the inferior margin of the mandibular body and lies behind rather than below the tongue root 


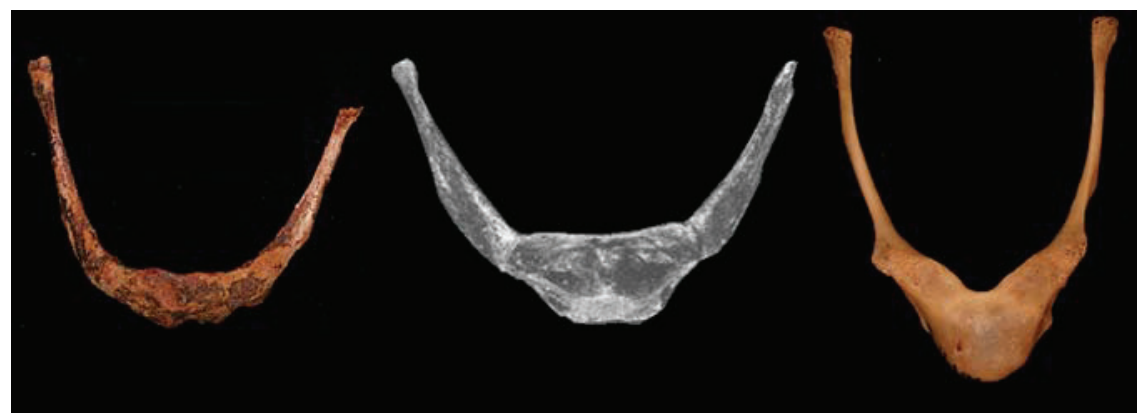

Figure 1. The hyoid bone viewed superiorly in humans (left), Neanderthals (center), and chimpanzees (right). Note that the left greater horn of the human specimen is incomplete.

(Falk 1975). Furthermore, the shape of the hyoid body differs both between the great apes and humans and between African and Asian great apes: African ape hyoid bodies are expanded anteriorly with a curved bulla, which reflects the superior extension of the laryngeal air sac into the hyoid body (e.g., Miller 1941; Aiello and Dean 1990). The African ape hyoid body can appear almost translucent due to the thinness of the bone. Although orangutans do not have an extensive hyoid body bulla, they nevertheless have the most extensive and largest air sac system of all Hominoidea (Swindler and Wood 1973). The differences in hyoid body shape between the African and Asian great apes might be linked not to the presence or absence of the air sac system per se but to differences in how the subhyoid portion of the air sac reaches the pectoral and axillary regions in African and Asian great apes.

Laryngeal Air Sac Anatomy. Based on their origin as lateral outgrowths from the ventricular recesses formed by the inferior thryo-arytenoid fold and the vocal folds, the air sacs observed in all great apes are classified as lateral ventricular sacs (Hewitt et al. 2002, Kelemen 1963; Negus 1949; Avril 1963; Brandes 1932; Fick 1895; Miller 1941; Nemai and Kelemen 1929). However, in African great apes, the ventricular processes fuse to a single air sac space within the confinement of the hyoid body (see Figure 2 for illustration) (Avril 1963; Miller 1941). It is this fused "stem" of the subhyoid portion of the air sac that emerges midsagittally through the thyrohyoid membrane of African great apes (Avril 1963; Miller 1941; Swindler and Wood 1973). It can therefore be argued that an air sac system with midsagittal plane exit point from the larynx complex forms a hyoid body bulla. That this might be the case is further supported by other primate species with air sac systems that differ from that of the Hominoidea (lateral ventricular sacs system) but that still leave the larynx complex via the thyrohyoid membrane in the midsagittal plane. Cercopithecoids (e.g., Papio) have subhyoid air sac systems that originate directly from the hyoid space rather than the laryngeal ventricles (Hewitt et al. 2002). However, they share the point of emergence of the air sac 

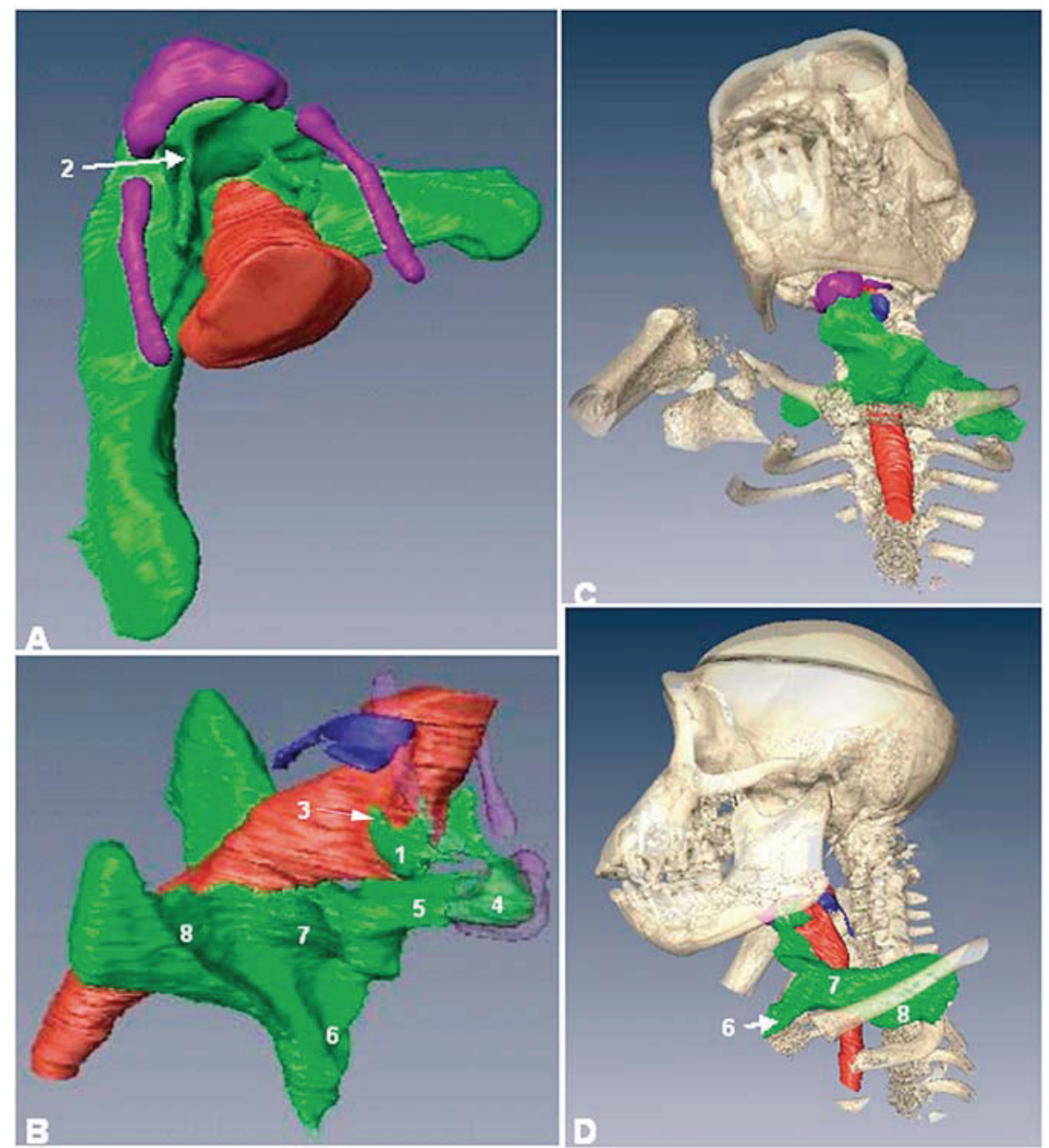

Figure 2. Three-dimensional computerized tomography scan reconstruction of air sac system and surrounding soft and hard tissue of a 4- to 5-year-old chimpanzee: A, superior view; B, right lateral view; C, anteroinferior view; D, left lateral view. Pale yellow, skeletal elements; purple, hyoid bone; red, trachea; blue, esophagus; green, air sacs. 1, ventricular processes; 2, thyrohyoid process; 3 , submaxillary sac (not yet fully developed); 4, hyoid sac; 5 , midline process; 6 , episternal sac; 7 , pectoral sac; 8 , infraclavicular sac.

with the African great apes (Avril 1963). In Papio and Ateles, bulla formation of the hyoid body is observed (Hilloowala 1975; Swindler and Wood 1973).

Orangutans contrast from this arrangement in that their ventricular processes pierce the thyrohyoid membrane laterally, below the greater horns of the hyoid (Fick 1895) rather than through the anterior aspect of the thyrohyoid membrane in the midsagittal plane. The two air sacs then fuse to a single sac below and anterior 
to the hyolaryngeal complex. The orangutan hyoid body on the other hand does not show an extensive, thin-walled bulla formation as seen in the African great apes, although some anterior swelling is observed in the superoanterior wall of the orangutan hyoid body (for an image of an orangutan hyoid body, see, e.g., Nemai and Kelemen 1929). The reason for the difference in these arrangements is not clear-perhaps it links to differences in suprahyoid musculature insertion on the hyoid between African apes and orangutans. For example, the anterior belly of the digastric muscle is missing in orangutans but present in African great apes (and humans), and the posterior digastric belly inserts into the angle of the mandible rather than the hyoid bone (Fick 1895; Nemai and Kelemen 1929; Swindler and Wood 1973). Perhaps this leads to a different arrangement in available space for the subhyoid air sac to emerge, but further studies of air sac development would be necessary to test such a hypothesis.

With regards to the development of great ape air sacs, only limited data are available. Studies by Miller (1941) and Nishimura et al. (2007) suggest that the development of air sacs in African great apes occurs entirely postnatally. The very limited data available for the gorilla indicate that the hyoid air sac is already shaping a small hyoid cavity before the age of 2 years (Miller 1941). A study of chimpanzee air sac development with magnetic resonance imaging in vivo in three chimpanzees between 1 month and 5 years of age (Nishimura et al. 2007) revealed an initial period of steady, relatively slow growth during early infancy up to 2 years of age. In this stage, the hyoid air sac continuously grows and is the most clearly visible part of the air sac system. In late infancy (2-5 years of age), a rapid descent and extension of the subhyoid part of the air sac system is observed. During this time, the air sacs reach the sternal level.

\section{Laryngeal Air Sac Function, and the Loss of this System in Human Evolu-}

tion. If data on the anatomy of the great ape air sac are relatively scarce, it is even less clear what the function of primate laryngeal air sacs is (e.g., Hewitt et al. 2002; see also Kelemen 1963; Negus 1949; Nemai 1920, 1926; Sonntag 1924). In some primate species, air sacs, in junction with the vocal folds, clearly play a role as a resonating chamber-especially in Cercopithecoidea, Alouatta (the howler monkey), and Hylobates (see Schön 1971; Schön Ybarra 1995; Hilloowala 1975). It has been suggested that air sacs can increase the duration and alter the formant frequencies of vocalization, perhaps as a means of exaggerating the body size of the caller (de Boer 2009; Hewitt et al. 2002; see Hilloowala and Lass 1978; for related arguments regarding vocal tract dimensions and the descended larynx, compare Fitch and Hauser 1995; Fitch 2000a, 2000b; Fitch and Reby 2001). Riede et al. (2008) found, using a physical model, that air sacs can increase vocal variability (both by extending the dynamic range and by increasing variability in vocal tract impedance). Nevertheless, both Riede et al. (2008) and de Boer (2009, 2012) also suggest that air sacs can introduce additional resonances into the vocal signal that would reduce the efficiency of a speech-like vocal communication system. 
Of all the Hominoidea, only modern humans and some of the gibbon species do not have an air sac system, and the possession of lateral ventricular air sacs is considered to be the ancestral state for the Hominoidea (Hewitt et al. 2002). This leads to further inquiries about the presence or absence of an air sac system in fossil hominoid taxa. The fossil record has yielded several complete or partial hyoids, of which the two best known are one from the Kebara 2 Neanderthal (Arensburg et al. 1989) and one (represented by the body only) from the Dikika Australopithecus afarensis (Alemseged et al. 2006). These two bones represent very different moments in the evolution of the hominins, after the split of the last common ancestor of modern humans and African great apes. Additionally, in Spain the El Sidron site, dated to about 43 kya, yielded a hyoid body assigned to Neanderthal that is very similar in size and shape to that of modern humans (Rodriguez et al. 2003), while the Sima de los Huesos site (also from Spain) has yielded two hyoid bodies, both assigned late subadult or adult developmental ages (Martinez et al. 2008), which are of great interest because they are attributed to middle Pleistocene European Homo (almost certainly ancestral to Neanderthals, and sometimes included in Homo heidelbergensis) and date to approximately 530 kya.

Aims of this Article. The specific purpose of this article is to describe the hyoid-air sac relationship in a chimpanzee, to provide a metrical analysis of hyoid characteristics in humans and in African apes that may relate to the presence or absence of a laryngeal air sac, and to characterize the fossil hyoids of extinct hominins in relation to those of these three living reference species. This article revises and updates the data given in an unpublished analysis of hyoid metrical variation (Clegg 2001) and that have been used in two previous articles to contextualize and aid interpretation of individual fossil hominin hyoid bones (Alemseged et al. 2006; Martinez et al. 2008). In the wider research context, our work also relates to speech origins. Assuming both that the presence of air sacs can reduce the perceptual ease of discrimination of speech sounds, as argued by de Boer $(2009,2012)$, and that the common human and African great ape ancestor had an air sac system like that of the extant African great apes (expanding from the laryngeal complex via the thyrohyoid membrane in the midsagittal plane), then it can be argued that the loss of the air sac system in hominins is a marker of an enhanced capacity for articulate speech. It would therefore be of great interest to know at what point in time human ancestors lost the air sac system.

\section{Materials and Methods}

Chimpanzee Air Sac System: Virtual Dissection To study air sac morphology and hyoid relationships in a representative chimpanzee, a set of three-dimensional computer tomography (CT) images of a chimpanzee cadaver was recorded in December 2007 at the Hospital Balgrist, Zurich, using a specimen from the A. H. Schultz and Primate Collections of the Anthropological Institute and Museum 
of the University of Zurich, Switzerland. The chimpanzee specimen (catalogue no. 7288, Zurich Collections) used for the surface reconstruction of the air sac system was a juvenile male. Age is estimated at 4-5 years of age. The specimen originally came from the Department of Anatomy, University of Zurich, and has been with the anthropology cadaver collections since 1966. The animal was a wet-preserved cadaver; conservation is maintained with formaldehyde solution (4\%). We used CT scan technology (Philips Brilliance 40 Medical Systems, Inc.; slice thickness, $0.67 \mathrm{~mm}, 0.33 \mathrm{~mm}$; tube voltage, $120 \mathrm{kV}$; tube current baseline, $120 \mathrm{~mA}$; field of vision, $160 \mathrm{~mm}$; all image matrices $512 \times 512 \times 512$ pixels). From the CT scans, the volume of the air sac system was segmented from their entrances in the laryngeal ventricles and reaching both supra- and infralaryngeal extensions using the software AMIRA (Visage Imaging Inc.). Segmenting means that the pixels of each slice image are assigned a label describing to which region or material the pixel belongs. A new data set is then created and a surface grid is produced from it that allows for making a three-dimensional view of the selected object's surface. All visualizations (slices, volume surface reconstructions) were produced with AMIRA 4.1.1.

African Ape and Human Hyoid Morphology: Osteological Study. African ape skeletal elements were from the Merfield and Congo expedition collections held by the Powell-Cotton Museum, Kent, England, and adult human skeletal elements were from the Christ Church Spitalfields collection held by the Natural History Museum, London, England. Hyoid bones were recorded for 118 adult individuals - 64 humans Homo sapiens (38 males, 23 females, 3 unsexed), 33 chimpanzees (Pan troglodytes; 7 males, 26 females), and 21 gorillas (Gorilla gorilla; 10 males, 11 females) — with additional measurements of the associated cranium and mandible when present. All species were assessed as adult on the basis of third molar in occlusion or, if the third molar was missing or impacted, tooth wear pattern on M1 and M2. The measurements taken are described in Table 1 , along with their abbreviations. Hyoid body measurements were also taken for a smaller number of infants and juveniles in the same collections (2 Homo sapiens, 17 Pan troglodytes, 21 Gorilla gorilla) and for an additional human sample of 27 infants, juveniles, and adolescents from the medieval skeletal assemblage from Wharram Percy, Yorkshire, England. Figure 1 illustrates examples of adult human, chimpanzee, and Neanderthal hyoid bones.

The hyoid bone measurements were based on those that Arensburg et al. $(1989,1990)$ used to analyze the Kebara 2 Neanderthal hyoid bone and human comparisons, with an additional new measurement that captures the variation found when comparing human and African ape hyoids. The African ape hyoid bodies are often expanded anteriorly with a curved bulla, which may reflect the superior extension against the dorsal hyoid body of the laryngeal air sac (e.g., Aiello and Dean 1990). Arensburg et al.'s (1989) anteroposterior thickness measurement (APT) is compromised as a thickness measurement in the African ape bones by the fact that the upper and the lower posterior margins of the hyoid body are not 
Table 1. Hyoid and Cranial Measurements (Unilateral Measurements Taken on Left Side Where Available)

ABBREVIATION MEASUREMENT

DESCRIPTION

Hyoid bone measurement (after Arensburg et al. 1989, 1990; except MAPT, defined for this study)

TML Total maximum length Total maximum length of the hyoid bone in the midsagittal plane, in projection from the distal end of the greater horns to the most anteromedial point of the body, with the greater horns attached to the body in their anatomical position

TMB Total maximum breadth Total maximum breadth of the hyoid bone in transverse plane, taken at the most external distal ends of the greater horns, with the greater horns attached to the body in their anatomical position

\begin{tabular}{ll}
\hline MTD & $\begin{array}{l}\text { Maximum transverse } \\
\text { diameter }\end{array}$ \\
\hline MMH & Maximum medial height \\
\hline APT & Anteroposterior thickness
\end{tabular}
Maximum transverse diameter of hyoid body

Maximum medial height of hyoid body (midsagittal distance between the superoposterior and inferoposterior borders of the hyoid body) Anteroposterior thickness of hyoid body in sagittal plane; one caliper branch tangent to upper and to lower posterior margins of hyoid body, and the other branch tangent to the most protruding anteromedial point of the hyoid body

\begin{tabular}{|c|c|c|}
\hline MAPT & $\begin{array}{l}\text { Maximum anteroposterior } \\
\text { thickness }\end{array}$ & $\begin{array}{l}\text { Chord length in sagittal plane, from medial point on } \\
\text { upper posterior margin of hyoid body, to the most } \\
\text { protruding anteromedial point of the hyoid body }\end{array}$ \\
\hline DPS & Depth of the posterior surface & $\begin{array}{l}\text { Depth of the posterior surface of the hyoid body, } \\
\text { measured from the upper and the lower posterior } \\
\text { margins of the hyoid body in the midsagittal plane }\end{array}$ \\
\hline LGH & Length of the greater horn & $\begin{array}{l}\text { Distal end to the lateral border of proximal articular } \\
\text { surface }\end{array}$ \\
\hline WGH & Width of the greater horn & $\begin{array}{l}\text { Inferosuperior width of greater horn taken at widest } \\
\text { point closest to hyoid body }\end{array}$ \\
\hline \multicolumn{3}{|c|}{ Skull measurements } \\
\hline U.face & Upper facial height & From nasion to alveolare \\
\hline Bizygo & Bizygomatic breadth & From zygion to zygion \\
\hline IPL & Internal palate length & From orale to staphylion \\
\hline IPB & Internal palate breadth & From endomolare to endomolare \\
\hline MBB & $\begin{array}{l}\text { Mandibular bicondylar } \\
\text { breadth }\end{array}$ & From condylion to condylion \\
\hline MGB & Mandibular bigonial breadth & From gonion to gonion \\
\hline S.ht & Mandibular symphysis height & From gnathion to infradentale \\
\hline$\overline{\mathrm{ML}}$ & Mandibular length & $\begin{array}{l}\text { Horizontal distance from the posterior aspect of } \\
\text { condyles to gnathion }\end{array}$ \\
\hline $\mathrm{Hr}$ & $\begin{array}{l}\text { Maximum height of } \\
\text { mandibular ramus }\end{array}$ & From gonion to uppermost part of condyle \\
\hline C-E & Cranial base length & Hormion to endobasion \\
\hline $\mathrm{O}-\mathrm{E}$ & Total cranial base length & Orale to endobasion \\
\hline TP-TP & Bitympanic width & $\begin{array}{l}\text { Cranial base width at most inferior point of lateral } \\
\text { end of tympanic plates }\end{array}$ \\
\hline SM-SM & Bistylomastoid width & $\begin{array}{l}\text { Width between central points in the left and right } \\
\text { stylomastoid foramina }\end{array}$ \\
\hline $\mathrm{CC}-\mathrm{CC}$ & Bicarotid canal width & $\begin{array}{l}\text { Width between central points in the left and right } \\
\text { carotid canals }\end{array}$ \\
\hline TP-PA & Tympanic-petrous length & $\begin{array}{l}\text { Length between most inferior point of lateral end } \\
\text { of tympanic plate and anteriormost point of inferior } \\
\text { surfaces of petrous temporal bone }\end{array}$ \\
\hline
\end{tabular}


equivalent in their posterior extension, since the upper margin typically extends a greater distance posteriorly in these species. The new measurement MAPT controls for this shape characteristic.

The dimensions of the Dikika hyoid were taken from Alemseged et al. (2006), whose comparative analysis of its form used an unpublished earlier version of the chimpanzee and gorilla data reported here, with some additional cases (F. Spoor, pers. comm.). All metrical data reported in the present article were collected by M.C. and J.S. during 2006 and 2007 (new or remeasured) and supersede the values reported in an earlier iteration (Clegg 2001) and that were used by Alemseged et al. (2006) and by Martinez et al. (2008). The comparative sample used by Alemseged et al. (2006) also included only three human subadults (two from Christ Church, Spitalfields, and one other). For the present study, we expanded the human subadult sample to 29 individuals, so that our analysis of Dikika in the present article could make comparisons with a more appropriately age-matched sample from all three extant species. In these respects, the present comparative analysis of the morphology of the Dikika hyoid body should be seen as complementing that of Alemseged et al. (2006). The dimensions of the Kebara 2 hyoid were taken from Arensburg et al. (1989), except MAPT, which was taken from a high-quality cast.

Statistical Analysis. Descriptive statistics were obtained for all adult hyoid dimensions measured in the three extant species, and discrimination function analysis of these three groups was used to classify extant specimens from each of two extinct species, Australopithecus afarensis and Homo neanderthalensis. The scaling of dimensions was estimated by reduced major axis regression (Sawada 1999), and the test for isometry was whether or not a value of 1.0 fell within the $95 \%$ confidence interval for the slope of the log-log regression.

Predicted morphological relationships of the hyoid with the craniofacial and laryngeal complexes include those between the total maximum breadth of the hyoid (distance between the distal greater horns in their anatomical positions) and transverse diameter of the basal oropharynx, and between total maximum length of the hyoid and midsagittal diameter of the basal oropharynx and tongue root. Soft tissue dimensions were not available to test these predictions in our samples. To explore these relationships indirectly, a set of cranial dimensions was measured in the adult human and African ape sample (Table 2), and bivariate correlations were calculated to estimate the covariance of each hyoid dimension with the most highly correlated cranial variable in the three extant species. The expectation was that hyoid widths would scale most closely with one or more width measurement on the cranial base or facial skeleton, and that hyoid lengths would scale most closely with one or more cranial base length measurement.

Statistical analyses were undertaken using SPSS for Windows, version 14.0 (SPSS Inc. 2005), and the reduced major axis regression add-in for Microsoft Excel (Sawada 1999). 
Table 2. Descriptive Statistics [mm; mean \pm SD ( $n$; range)] for Adult Human, Chimpanzee, and Gorilla Hyoid Bones

\begin{tabular}{llll} 
& \multicolumn{1}{c}{ SPECIES } & \\
& HOMO & PAN & GORILLA \\
\hline TML & $36 \pm 4.1$ & $48.3 \pm 4.5$ & $67.3 \pm 1.1$ \\
& $(n=37 ; 27.8-42.4)$ & $(n=5 ; 43.3-55)$ & $(n=2 ; 66.5-68)$ \\
\hline TMB & $40.7 \pm 5.2$ & $31.2 \pm 5.4$ & $32.8 \pm 5.9$ \\
& $(n=21 ; 30.7-50.6)$ & $(n=5 ; 24.1-37.4)$ & $(n=2 ; 28.6-37)$ \\
\hline MTD & $23.4 \pm 2.5$ & $23.5 \pm 2.6$ & $25 \pm 3.6$ \\
& $(n=62 ; 17.1-29.9)$ & $(n=31 ; 17.7-29)$ & $(n=18 ; 18.8-31.5)$ \\
\hline MMH & $10.6 \pm 1.2$ & $11.1 \pm 1.7$ & $13.1 \pm 3.3$ \\
& $(n=63 ; 8-13.7)$ & $(n=32 ; 8-14.4)$ & $(n=18 ; 7.5-18.2)$ \\
\hline APT & $5.1 \pm 1$ & $7.3 \pm 1.3$ & $11.6 \pm 3$ \\
& $(n=63 ; 3.1-7.4)$ & $(n=31 ; 5.4-10.4)$ & $(n=17 ; 6.2-17.5)$ \\
\hline MAPT & $5.1 \pm 1$ & $13.4 \pm 1.9$ & $17.1 \pm 2.9$ \\
& $(n=63 ; 3.4-7.6)$ & $(n=31 ; 8.7-16.8)$ & $(n=17 ; 11.5-21.4)$ \\
\hline DPS & $2 \pm 0.7$ & $6.6 \pm 1.4$ & $9.9 \pm 2.4$ \\
& $(n=63 ; 0.9-3.8)$ & $(n=31 ; 3.9-10)$ & $(n=17 ; 5.7-14.6)$ \\
\hline LGH & $28.1 \pm 3.8$ & $33.6 \pm 5.4$ & $40 \pm 7.6$ \\
& $(n=41 ; 19.2-35.5)$ & $(n=27 ; 26-51.6)$ & $(n=15 ; 30.5-51.8)$ \\
\hline WGH & $7 \pm 1.1$ & $7 \pm 1.3$ & $9.5 \pm 2.1$ \\
& $(n=49 ; 5.2-9.3)$ & $(n=28 ; 4-11.7)$ & $(n=17 ; 6-13)$ \\
\hline
\end{tabular}

For abbreviations, see Table 1.

\section{Results}

Our results support a clear distinction between the African ape and human hyoid body morphologies, which (as our virtual dissection confirms) relate to underlying contrasts in the presence or absence of the infrahyoid extension of the air sac system. Multivariate analyses support the reconstruction of a chimpanzee-like air sac system in earlier hominins (A.afarensis) and of the absence of this system in later hominins (H. heidelbergensis, $H$. neanderthalensis). Overall dimensions of the hyoid (body plus greater horns) are associated across species with width and length variation in the cranial base.

The Chimpanzee Air Sac System. Our virtual dissection study yielded a clear illustration of the relationship between the laryngeal air sac and the hyoid body in an African ape. Figure 2 shows an image of the head and neck of the male subadult chimpanzee, consisting of a midsagittal plane slice. The expansions of the hyoid air sac and the midline process (labeling of air sacs as defined by Miller 1941) are clearly visible. Some other clearly identifiable anatomical structures are labeled as well. Figure 3 shows a superimposition of the surface reconstruction of the air sac system combined with a midsagittal plane slice. In Figure 3, 
only features of the air sac system lying anterior to the midsagittal plane slice are visible. However, clearly visible is the greater horn of the hyoid, as well as the submaxillary air sac, the infrahyoid air sac (midline passage), infraclavicular air sac, and the episternal air sac. Since this is a juvenile animal, the episternal air sac did not reach farther down than approximately halfway to the manubrium. Figure 4 shows another view of a combination of the surface reconstruction of the air sac system and in this case a coronal section (approximately at the level of the sphenomaxillary border, behind the sphenoid sinus; the anterior third of the temporal bone, but behind the maxilla and mandible is visible). This image has been chosen because it shows where and how the air sac system branches off the pharynx and trachea.

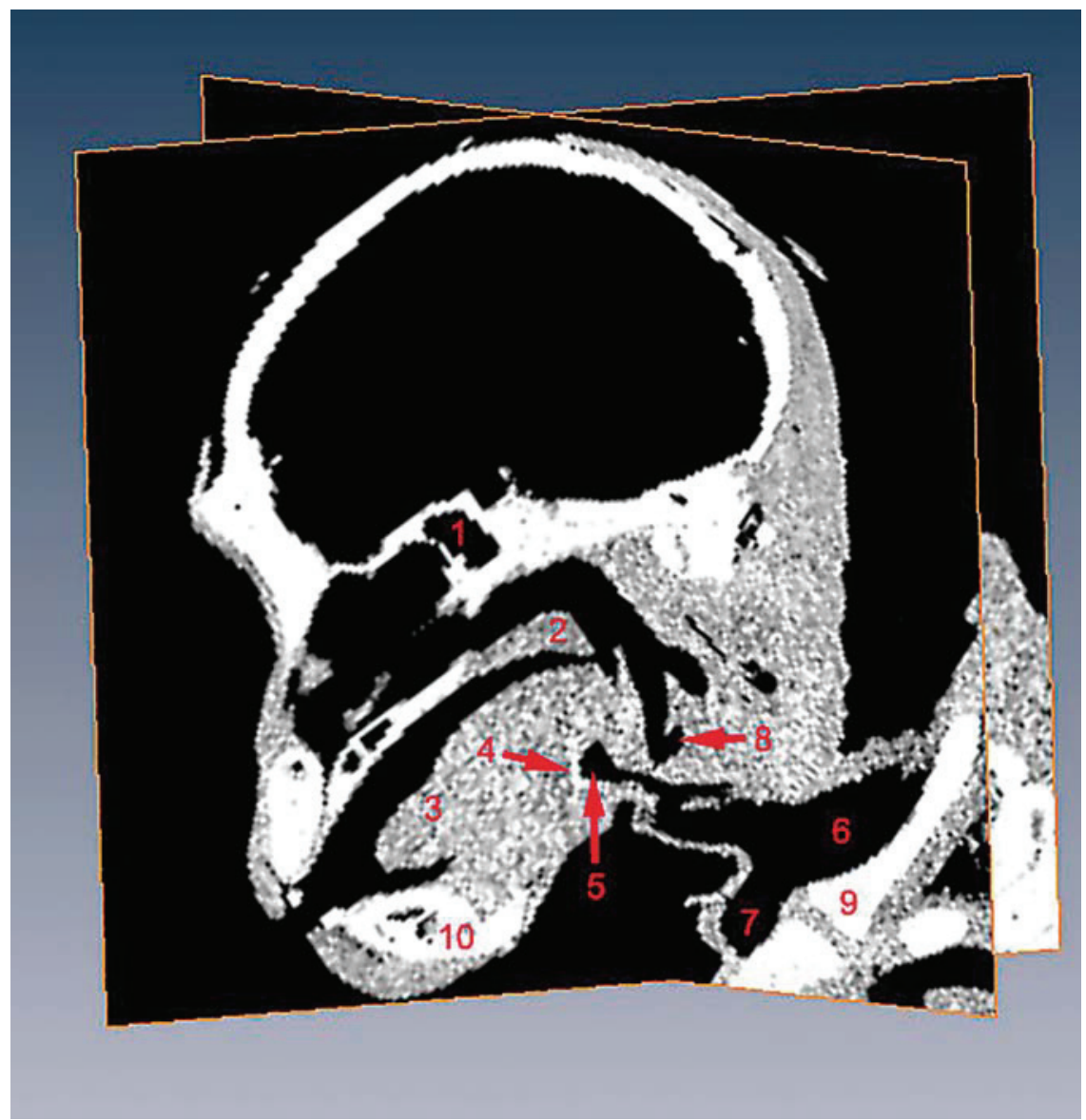

Figure 3. Combination of midsagittal section and surface reconstruction of the air sac system and the hyoid. 1, sphenoid sinus; 2, soft palate; 3 , tongue; 4, hyoid body; 5 , infrahyoid air sac (midline process); 6, pectoral air sac; 7, episternal air sac; 8, submaxillary air sac; 9 , clavicle; 10 , mandible. 


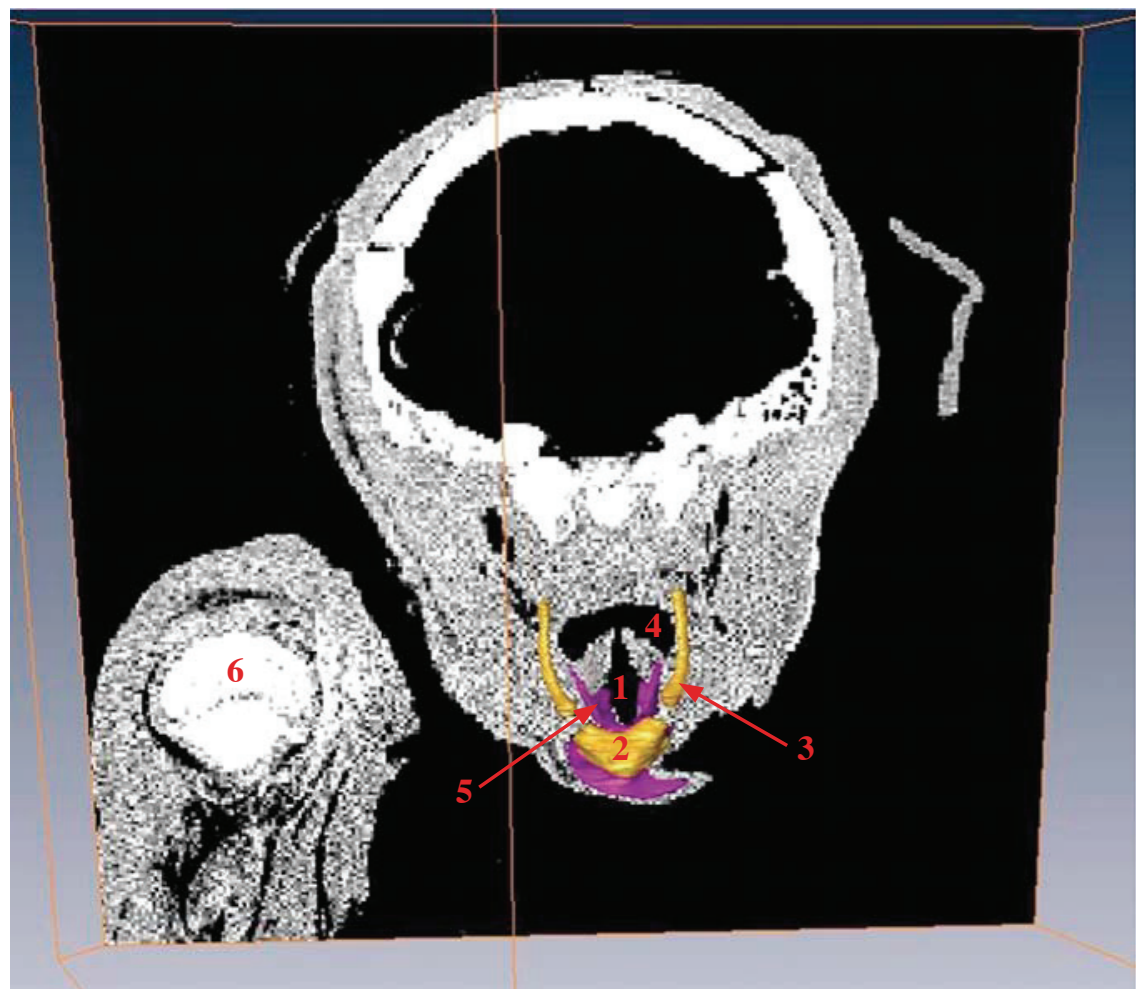

Figure 4. Anterior combination view of coronal slice and surface reconstruction of air sac system and hyoid body and greater horns. 1, trachea; 2, hyoid body; 3, greater horn; 4, pharynx 5 , submaxillary air sac; 6 , humerus head.

Additional interesting details are visible in the image of the surface reconstruction of the hyoid bone and air sac system only, as shown in Figure 5. Although the view on the hyoid air sac is obscured by the hyoid bone, relationships between the different air sacs show quite well. Ventricular and thyrohyoid processes are

Figure 5 (opposite, top). Left lateral view, air sac system and hyoid bone surface reconstruction only. 1 , hyoid body; 2 , greater horn; 3 , submaxillary air sac; 4 , ventricular process; 5 , thyrohyoid process; 6 , anterior midline process; 7 , episternal air sac; 8 , pectoral air sac; 9 , infraclavicular air sac.

Figure 6 (opposite, bottom). Posterior view: surface reconstruction of air sac system and hyoid bone only. 1 , hyoid body; 2 , greater horn; 3 , ventricular process (connecting pharynx to air sac system); 4, connection between anterior trachea wall and volume of the air sac system (trachea not reconstructed); 5, submaxillary air sac; 6 , left thyrohyoid process, leading to 7 , hyoid air sac; 8 , midline process; 9 , vestigial right thyrohyoid process, ending blind; 10, pectoral air sac; 11, infraclavicular air sac. 
Hominin and African Ape Hyoid / 651
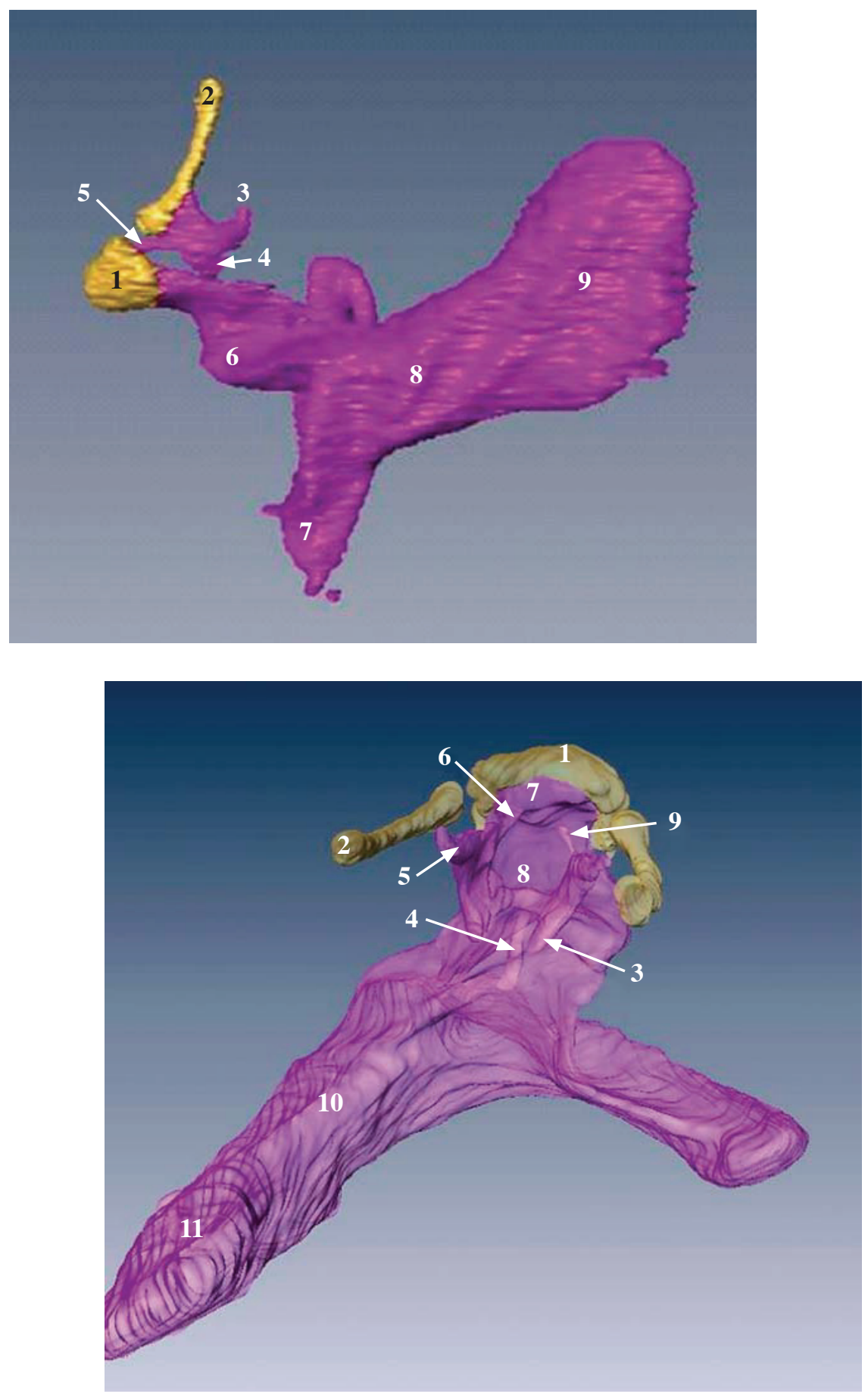
visible, too, although the exact connection to the air sacs is somewhat unclear in this image. Figure 6 further visualizes the connections among the pharynx, trachea, and the processes of the air sac system. The air sac system is shown from posterior, and the surfaces are rendered semitransparent for better visualization of overlaying structures. The image first shows that the left side is the dominant part of the air sac system of this specimen. The image also reveals not only that the ventricular processes lead to the left and right sides of the air sac system but also that there is a connection, located anteriorly and in the midline between the air sac system and the trachea. The air sac system becomes asymmetric just after the processes leading to the submaxillary air sacs are branching off: the left thyrohyoid process clearly connects to the hyoid air sac, and the left midline process then leads to left and right pectoral air sacs, episternal air sac, and left and right infraclavicular air sacs. The right thyrohyoid process on the other hand ends blind without connecting to the hyoid air sac.

Adult Human and African Ape Hyoids. The mean and range of values for metrical attributes of adult hyoids for each species are shown in Table 2, with typical examples shown in Figure 7A (see also Table 3 for hominin metrics). Three distinct patterns emerge. First, adult African ape hyoids have an anteroposteriorly expanded body compared with the human hyoids, with the presence of a posterior cavity or bulla reflected in the large differences between humans and the African apes in depth of the posterior surface of the body (DPS) and its maximum anteroposterior thickness (MAPT). This contrast is not found in other adult hyoid body dimensions (body height, MMH, or body width, MTD). Second, in humans the maximum width across the distal tips of the articulated greater horns (TMB) is usually slightly greater than the maximum length (TML; distal greater horn tip to most anterior point of the hyoid body in the midline). A different pattern is found in the African ape hyoids, which have much greater maximum lengths. Third, within the African apes, the mean anteroposterior dimensions of the adult gorilla hyoid bodies are greater than those of the adult chimpanzee hyoid bodies, although the bones of these two species are not statistically distinguishable in the other two dimensions (maximum transverse diameter, MTD, and maximum medial height, MMH). These contrasts are confirmed by the $t$-tests of differences between means for each possible pairing of species (Table 4).

In the discriminant function analysis some of the hyoid measurements were excluded. TML and TMB were excluded because the sample of articulated bodies and greater horns in Gorilla was too small to make the analysis meaningful with these measurements included. APT was excluded to prevent redundancy, given the inclusion of the new alternative measurement MAPT.

The first discriminant function analysis included measurements from both the hyoid body and the (disarticulated) greater horns. The coefficients and the structure matrix (Table 5) indicate that discriminant function 1, which accounts for $96 \%$ of the variance (Wilks's $\lambda=0.032, p<0.001$ ), reflects primarily variation in the anteroposterior depth of the body. MAPT and DPS have the highest 
Table 3. Measured Dimensions (mm) for Fossil Hominin Hyoids

\begin{tabular}{|c|c|c|c|c|c|c|c|c|c|}
\hline & TML & TMB & MTD & MMH & APT & MAPT & DPS & LGH & WGH \\
\hline $\begin{array}{l}\text { Dikika Australopithecus } \\
\text { afarensis }^{1}\end{array}$ & - & - & 11.7 & 7.7 & - & - & 4.7 & - & - \\
\hline $\begin{array}{l}\text { Atapuerca Homo } \\
\text { heidelbergensis, } \\
\text { AT- } 1500^{2}\end{array}$ & - & - & 21.8 & 10.8 & 6.8 & - & 2.8 & - & - \\
\hline $\begin{array}{l}\text { Atapuerca Homo } \\
\text { heidelbergensis, } \\
\text { AT- } 2000^{2}\end{array}$ & - & - & 18.6 & 10.2 & 6.7 & - & 1.6 & - & - \\
\hline SDR-034 Neanderthal ${ }^{3}$ & - & - & - & 10.5 & 5.5 & - & 2.6 & - & - \\
\hline Kebara Neanderthal $^{4}$ & 35.5 & 45.0 & 24.6 & 13.4 & 5.8 & 8.0 & 3.8 & 25.0 & 5.2 \\
\hline
\end{tabular}

For abbreviations, see Table 1.

${ }^{1}$ Juvenile, from Alemseged et al. (2006), online supplementary material.

${ }^{2}$ From Martinez et al. (2008); both specimens are described as late subadult or adult.

${ }^{3}$ From Rodriguez et al. (2003); El Sidron specimen.

${ }^{4}$ From Arensburg et al. (1989), except MAPT, taken from a cast.

Table 4. $t$-Tests for Comparison of Means for Adult Hyoid Bone Measurements (Estimated with or without Equality of Variance Assumed, According to Results of Levene's Test for Each Paired Comparison)

\begin{tabular}{lccc} 
MEASURE & \multicolumn{3}{c}{ SPECIES } \\
& HOMO/PAN & HOMO/GORILLA & PAN/GORILLA \\
\hline TML & $<0.001$ & $<0.001$ & 0.003 \\
TMB & 0.001 & 0.056 & 0.744 \\
MTD & 0.872 & 0.094 & 0.094 \\
MMH & 0.229 & 0.006 & 0.020 \\
APT & $<0.001$ & $<0.001$ & $<0.001$ \\
MAPT & $<0.001$ & $<0.001$ & $<0.001$ \\
DPS & $<0.001$ & $<0.001$ & $<0.001$ \\
LGH & $<0.001$ & $<0.001$ & 0.008 \\
WGH & 0.983 & $<0.001$ & $<0.001$ \\
\hline
\end{tabular}

For abbreviations, see Table 1. Significance levels: $p<0.002$ for $\alpha=0.05$ after applying Bonferroni's correction for multiple comparisons ( $n=27$ tests).

correlations on this factor. This analysis shows a clear division between humans and the African apes (Figure 8A). Human hyoids have a shallow body compared with the African ape species. Discriminant function 2 accounts for only $4 \%$ of the variance (Wilks's $\lambda=0.583, p<0.001$ ) and is therefore not considered further. All 
Table 5. Standardized Canonical Discriminant Function Coefficients and Structure Matrix (Hyoid Body and Disarticulated Greater Horns, All Three Extant Species, Adults Only).

\begin{tabular}{lcc} 
MEASURE & \multicolumn{2}{c}{ DISCRIMINANT FUNCTION } \\
& 1 & 2 \\
\hline Standardized canonical discriminant function coefficients & & \\
DPS & 0.615 & 0.508 \\
LGH & -0.036 & 0.155 \\
MAPT & 0.985 & -0.579 \\
MMH & -0.603 & -0.202 \\
MTD & -0.375 & -0.091 \\
WGH & -0.073 & 1.044 \\
Structure matrix & & \\
DPS & 0.534 & 0.440 \\
LGH & 0.215 & 0.396 \\
MAPT & 0.762 & 0.149 \\
MMH & 0.075 & 0.397 \\
MTD & 0.041 & 0.266 \\
WGH & 0.149 & 0.867 \\
\hline
\end{tabular}

For abbreviations, see Table 1.

Table 6. Classification of Hyoid Bones using Discriminant Function (Hyoid Body and Disarticulated Greater Horns, All Three Extant Species, Adults Only; Kebara Hyoid Included as Ungrouped Case)

\begin{tabular}{lcccr} 
SPECIES & \multicolumn{2}{c}{ PREDICTED GROUP MEMBERSHIP } & TOTAL \\
& HUMAN & CHIMPANZEE & GORILLA & \\
\hline Human & 40 & 0 & 0 & 40 \\
Chimpanzee & 0 & 26 & 0 & 26 \\
Gorilla & 0 & 1 & 12 & 13 \\
Kebara (ungrouped) & 1 & 0 & 0 & 1 \\
\hline
\end{tabular}

the humans and chimpanzees and all but one of the gorillas were correctly classified by this analysis (Table 6 ).

The second discriminant function analysis included measurements from the hyoid body only, enabling a larger sample to be used (Figure 8B). The coefficients and the structure matrix (Table 7) indicate that discriminant function 1, which accounts for $99.3 \%$ of the variance (Wilks's $\lambda=0.05, p<0.001$ ), also reflects variation in the anteroposterior depth of the body. MAPT and DPS, which diagnose hyoid body thickness differences between humans and African apes, again have 
the highest correlations on this factor, confirming the first analysis. Classification results were also similar, although the inclusion of a larger number of individuals resulted in three chimpanzee hyoids being misclassified as gorilla and three gorilla hyoids being misclassified as chimpanzee (Table 8).

Kebara Adult Neanderthal Hyoid. The measurements of the adult Kebara 2 hyoid fall within the observed range for adult human hyoids in almost all dimensions (Tables 2 and 3). The exception is MAPT, for which the Kebara value of 8.0 $\mathrm{mm}$ is marginally higher than the observed range for the human sample (3.4-7.6 $\mathrm{mm})$. This higher value for MAPT reflects the relatively pronounced medial crest for attachment of the geniohyoid muscle, which Arensburg et al. (1989) suggested would have been unusually robust given the large size of the associated Kebara 2 mandible. Compared with the African apes, the Kebara hyoid is smaller than the observed range for total length (TML) and for length of the greater horn (LGH), is wider between the distal tips of the articulated greater horns (TMB), and is shallower in body depth (DPS, MAPT). This is consistent with the human pattern. The Kebara hyoid falls within the observed range for all three species for other, less differentiating, dimensions (MTD, MMH, WGH). The discriminant functions classify the Kebara hyoid as human in both cases (based on body and horns, and on body only; see Tables 6 and 8).

Subadult Human and African Ape Hyoids. The contrasts found in the adult hyoids are also found in the subadults (for typical examples, see Figure 7B). Compared with humans, the subadult African ape hyoids have an anteroposteriorly expanded body with the presence of a posterior cavity or bulla, as can be seen

Table 7. Standardized Canonical Discriminant Function Coefficients and Structure Matrix (Hyoid Body Only, All Three Extant Species, Adults Only)

\begin{tabular}{lrr} 
MEASURE & \multicolumn{2}{c}{ DISCRIMINANT FUNCTION } \\
& 1 & 2 \\
\hline Standardized canonical discriminant function coefficients & & \\
DPS & 0.649 & 0.683 \\
MAPT & 0.949 & -0.616 \\
MMH & -0.610 & 0.547 \\
MTD & -0.417 & 0.236 \\
Structure matrix & & \\
DPS & 0.577 & 0.812 \\
MAPT & 0.730 & 0.114 \\
MMH & 0.086 & 0.773 \\
MTD & 0.035 & 0.395 \\
\hline
\end{tabular}

For abbreviations, see Table 1. 

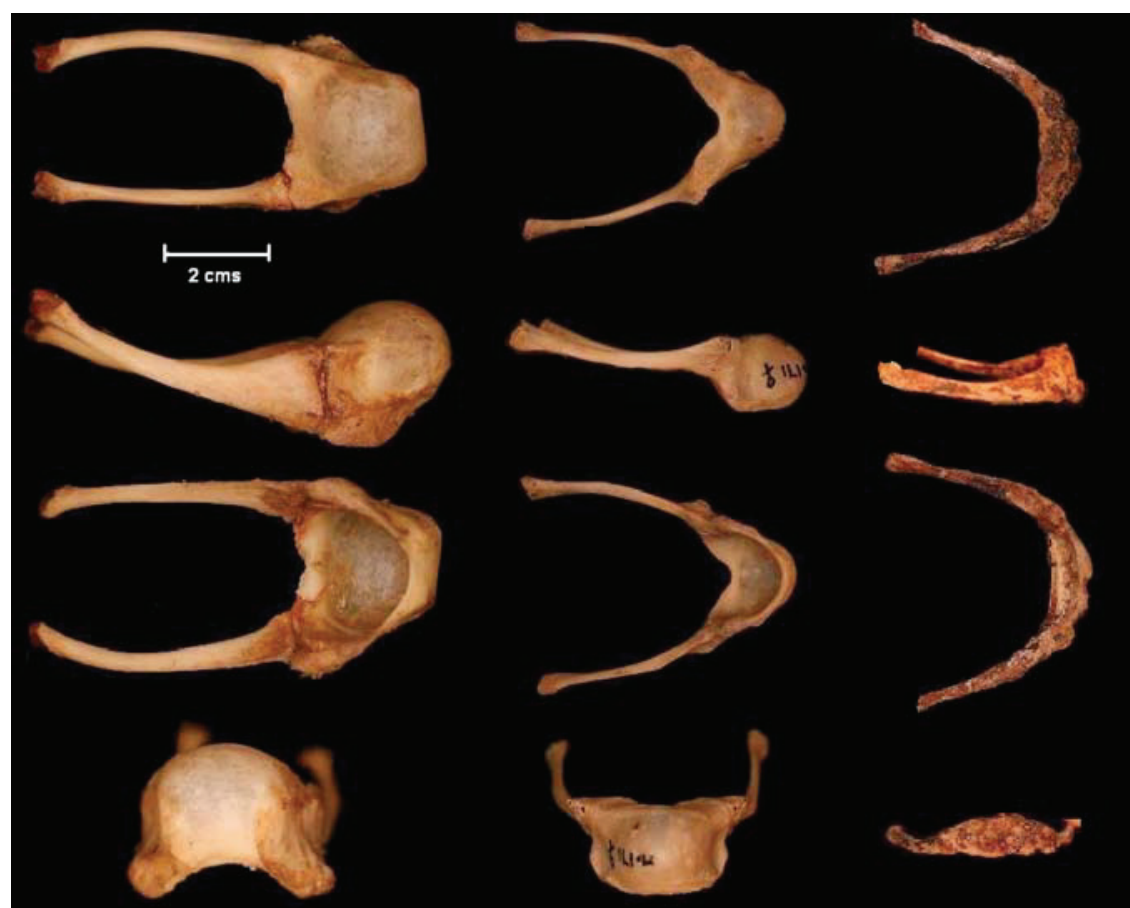

Figure 7a. Adult hyoid bones of the three extant species (left to right, Gorilla gorilla, Pan troglodytes, Homo sapiens). Specimen details: Gorilla gorilla adult male (M135, PowellCotton Museum); Pan troglodytes adult female (M171, Powell-Cotton Museum); Homo sapiens adult male (2681, Spitalfields, Natural History Museum London). Orientations of views (top to bottom): superior, right lateral, inferior, anterior.

Table 8. Classification of Hyoid Bones using Discriminant Function (Hyoid Body Only, All Three Extant Species, Adults Only; Kebara Hyoid Included as Ungrouped Case)

\begin{tabular}{|c|c|c|c|c|}
\hline & HUMAN & CHIMPANZEE & GORILLA & \\
\hline Human & 62 & 0 & 0 & 62 \\
\hline Chimpanzee & 0 & 27 & 3 & 30 \\
\hline Gorilla & 0 & 3 & 14 & 17 \\
\hline Kebara (ungrouped) & 1 & 0 & 0 & 1 \\
\hline
\end{tabular}




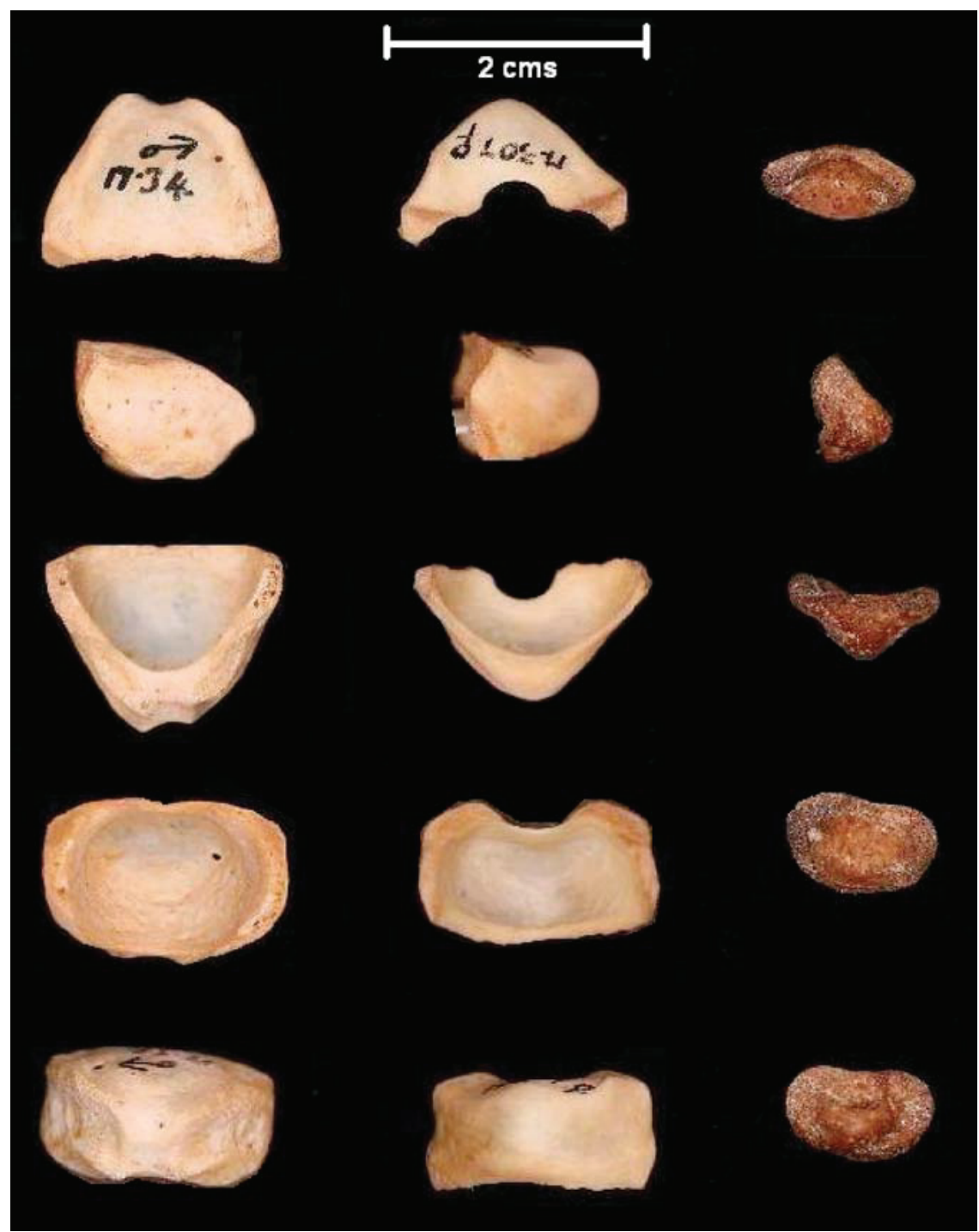

Figure 7b. Infant/juvenile hyoid bones of the three extant species (left to right, Gorilla gorilla, Pan troglodytes, Homo sapiens). Specimen details: Gorilla gorilla juvenile male (M34, juvenile with adult M1 but not M2 erupted, Powell-Cotton Museum); Pan troglodytes infant/juvenile female (M507, juvenile with erupted deciduous dentition but prior to adult M1 eruption, Powell-Cotton Museum); Homo sapiens infant/juvenile male (2735, age $\sim 3$ years, Spitalfields, Natural History Museum London). Orientations of views (top to bottom): superior, right lateral, inferior, posterior, anterior. 


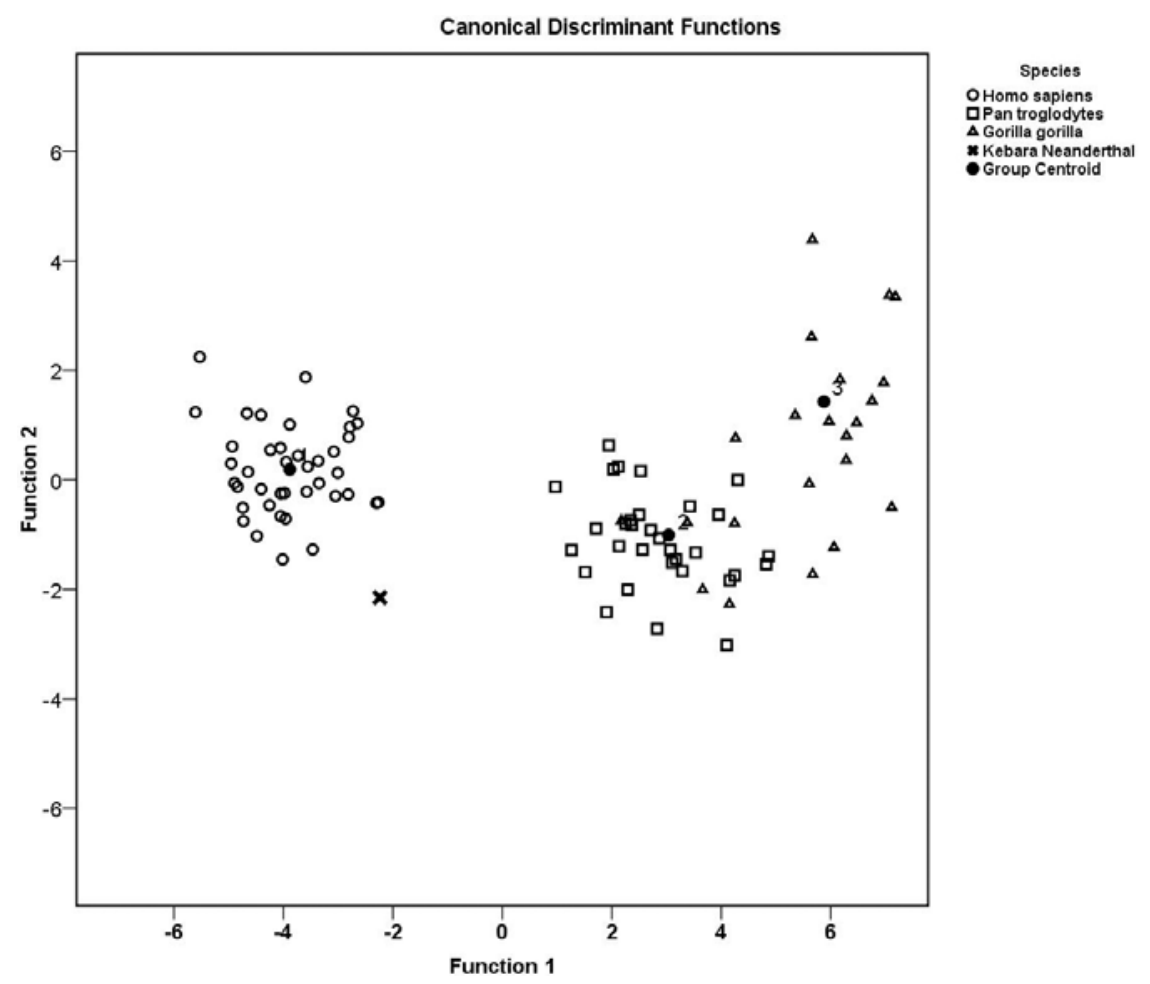

Figure 8a. Discriminant function plot for all groups (humans, chimpanzees, and gorillas, adults only) with the position of the Kebara 2 hyoid also shown, for dimensions of hyoid body and of disarticulated greater horn (see Tables 5 and 6).

in plots of the depth of the posterior surface (DPS) against height (MMH) (see Figure 9A). The ontogenetic scaling trends, summarized in Table 9, indicate that at all ages, the human values for DPS are very significantly lower than those of either African ape for any given value of MMH, as indicated by the different values for the intercept in the regression models. In African apes, the depth of the bulla (DPS) is greater from an early age and also hyperscales to the hyoid body's other linear dimensions (width, MTD, and height, MMH), reflecting the growth of the air sac system. Width (MTD) and height (MMH) of the hyoid body scale isometrically in chimpanzees, but MMH hyperscales relative to MTD in gorillas, reflecting an additional dimension of expansion of the gorilla hyoid bulla (the air sac growth presumably causing the hyoid bulla to expand superiorly as well as anteriorly, relative to its transverse diameter).

A discriminant function analysis of the subadult sample based on the three hyoid dimensions reported for the Dikika specimen (Alemseged et al. 2006) correctly classifies all the humans, and the majority of the chimpanzees and gorillas 


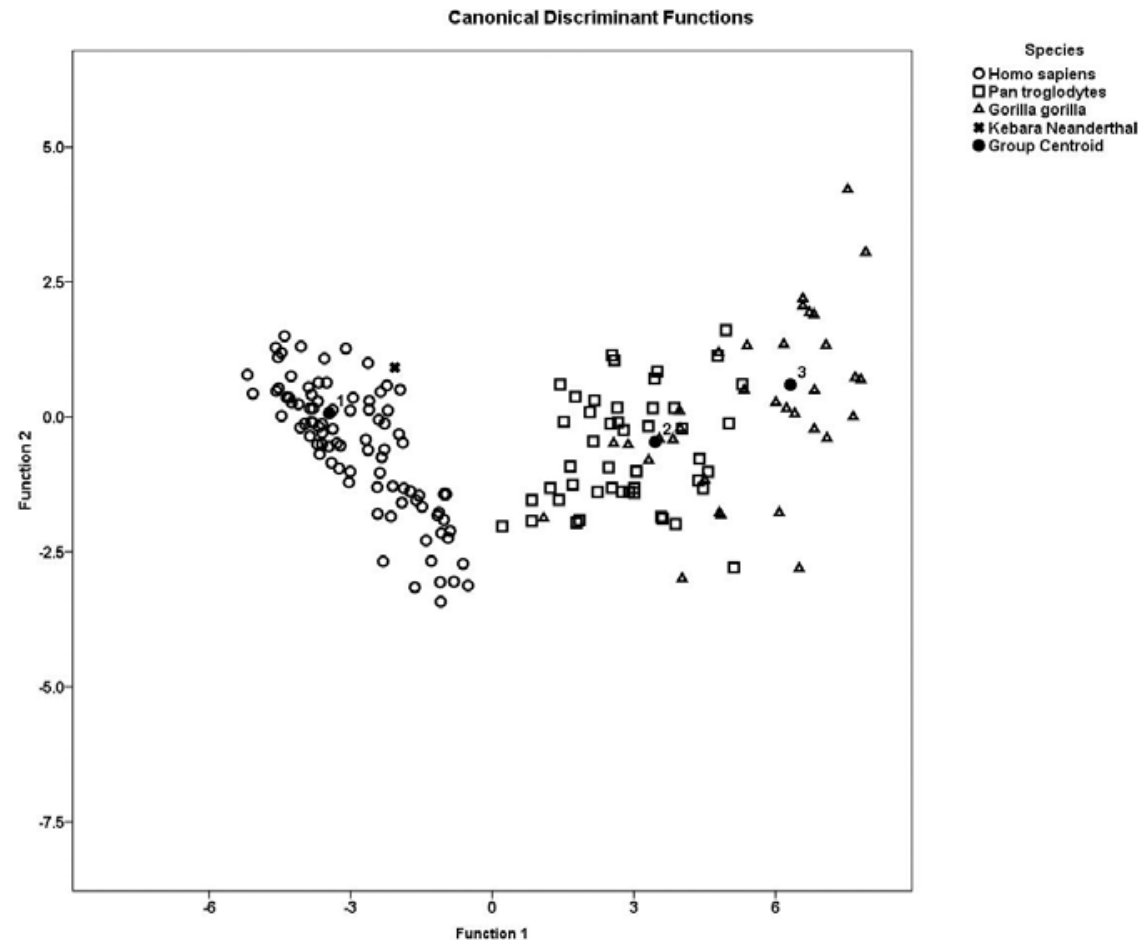

Figure 8b. Discriminant function plot for all groups (humans, chimpanzees, and gorillas, adults only) with the position of the Kebara 2 hyoid also shown, for dimensions of hyoid body only (see Tables 7 and 8).

(a small minority of each ape species being misclassified as the other; see Tables 10 and 11). The first discriminant function is the only statistically significant one (Wilks's $\lambda=0.129, p<0.001$ ), and DPS has the strongest loading on it. A high value for discriminant function 1 indicates a relatively deep posterior surface in proportion to the height of the hyoid body.

Dikika Juvenile Hyoid Dimensions. As previously observed by Alemseged et al. (2006), and now confirmed with a larger subadult human sample and with only subadults considered, the Dikika juvenile australopith hyoid is deep for its height (Figure 9) and width and is morphologically chimpanzee-like. This similarity applies both when comparing only subadults from the three extant species (Figure 9A), and when comparing across all observed age classes (Figure 9B; this graph also shows the plotted values for the two middle Pleistocene European hominin hyoids from Atapuerca SH, attributed here to H. heidelbergensis). The discriminant function analysis of subadult hyoid bodies, based solely on the 
three hyoid body dimensions reported for the Dikika specimen, also classifies this specimen with chimpanzees (Tables 10 and 11; Figure 10).

Adult Cranial and Hyoid Shape. Bivariate correlations between hyoid and cranial dimensions (Table 12) indicate that in the adults (with all three extant species pooled), hyoid total maximum length, greater horn length, and body thickness are all most highly correlated with cranial base length (orale-endobasion: vs. TML, Pearson's $r=0.92$; vs. LGH, Pearson's $r=0.75$; vs. DPS, Pearson's $r=$ 0.92 ; vs. MAPT, Pearson's $r=0.95$; all $p<0.01$ ). The scatter plot of MAPT versus O-E (Figure 11) suggests that this correlation may simply reflect a size effect in both dimensions that differentiates mean values in the three species. When the sample is split into the three extant species, this pattern of statistically significant

Table 9. Reduced Major Axis Models of the Scaling Relationships among Hyoid Body Dimensions in the Three Extant Species (Humans, Chimpanzees, Gorillas)

\begin{tabular}{|c|c|c|c|c|}
\hline MODEL & $n$ & $\begin{array}{l}\text { ISOMETRY/ } \\
\text { ALLOMETRY }\end{array}$ & RMA MODEL: $\mathrm{Y}=\mathrm{A}(\mathrm{SD})+\mathrm{B}(\mathrm{SD}) \mathrm{X}$ & PEARSON'S $r$ \\
\hline \multicolumn{5}{|l|}{ Subadults only } \\
\hline \multicolumn{5}{|l|}{ DPS vs. MMH } \\
\hline Humans & 28 & A & $\log$ DPS $=-3.97(0.37)+4.51(0.42) \log \mathrm{MMH}$ & 0.87 \\
\hline Chimpanzees & 17 & A & $\log$ DPS $=-0.98(0.19)+1.71(0.20) \log$ MMH & 0.88 \\
\hline Gorillas & 18 & I & $\log$ DPS $=-0.42(0.15)+1.28(0.14) \log \mathrm{MMH}$ & 0.89 \\
\hline \multicolumn{5}{|l|}{ DPS vs. MTD } \\
\hline Humans & 28 & A & $\log$ DPS $=-4.71(0.64)+4.21(0.57) \log$ MTD & 0.68 \\
\hline Chimpanzees & 17 & A & $\log$ DPS $=-1.15(0.29)+1.52(0.24) \log$ MTD & 0.75 \\
\hline Gorillas & 18 & A & $\log$ DPS $=-2.01(0.50)+2.23(0.39) \log$ MTD & 0.70 \\
\hline \multicolumn{5}{|l|}{ MMH vs. MTD } \\
\hline Humans & 29 & I & $\log \mathrm{MMH}=-0.16(0.16)+0.93(0.10) \log \mathrm{MTD}$ & 0.80 \\
\hline Chimpanzees & 17 & I & $\log \mathrm{MMH}=-0.10(0.21)+0.89(0.18) \log \mathrm{MTD}$ & 0.57 \\
\hline Gorillas & 18 & A & $\log \mathrm{MMH}=-1.24(0.40)+1.74(0.31) \log \mathrm{MTD}$ & 0.68 \\
\hline \multicolumn{5}{|l|}{ All ages pooled } \\
\hline \multicolumn{5}{|l|}{ DPS vs. MMH } \\
\hline Humans & 91 & A & $\log$ DPS $=-2.83(0.21)+3.09(0.21) \log$ MMH & 0.75 \\
\hline Chimpanzees & 48 & A & $\log$ DPS $=-1.40(0.27)+2.12(0.27) \log \mathrm{MMH}$ & 0.45 \\
\hline Gorillas & 35 & I & $\log$ DPS $=-0.91(0.29)+1.71(0.27) \log \mathrm{MMH}$ & 0.31 \\
\hline \multicolumn{5}{|l|}{ DPS vs. MTD } \\
\hline Humans & 90 & A & $\log$ DPS $=-1.73(0.19)+1.51(0.14) \log$ MTD & 0.39 \\
\hline Chimpanzees & 48 & A & $\log$ DPS $=-0.23(0.08)+0.76(0.06) \log$ MTD & 0.83 \\
\hline Gorillas & 35 & A & $\log$ DPS $=-2.57(0.55)+2.58(0.41) \log$ MTD & 0.35 \\
\hline \multicolumn{5}{|l|}{ MMH vs. MTD } \\
\hline Humans & 91 & A & $\log \mathrm{MMH}=0.36(0.05)+0.49(0.04) \log$ MTD & 0.58 \\
\hline Chimpanzees & 48 & A & $\log \mathrm{MMH}=0.55(0.07)+0.36(0.05) \log \mathrm{MTD}$ & 0.06 \\
\hline Gorillas & 36 & A & $\log \mathrm{MMH}=-0.97(0.25)+1.51(0.19) \log \mathrm{MTD}$ & 0.68 \\
\hline
\end{tabular}

For abbreviations, see Table 1. 
correlation only holds for the gorillas. However, there may be some overall functional significance in the fact that anteroposterior thickness of the hyoid body correlates with a cranial base dimension taken in the same plane.

Total maximum breadth of the hyoid is most highly correlated with bicarotid canal width (TMB vs. CC-CC, Pearson's $r=0.71 ; p<0.01$, all three species pooled). When broken down by species, this correlation is also supported by the chimpanzee data, and in humans, the highest correlation is with the closely related dimension of bistylomastoid width (TMB vs. SM-SM, Pearson's $r=0.50, p<$ 0.05 ); the gorilla sample is too small for independent assessment. This result is consistent with the soft tissue relationships: the styloid process is connected to the hyoid via the stylohyoid ligament and muscle, while the carotid artery passes just lateral to the superior thyroid cartilage and bifurcates at the level of the C3 vertebra, the internal branch passing more medially to enter the skull via the carotid canal. Bistylomastoid foramen and bicarotid canal width might therefore be expected to scale with the transverse diameter of the larynx and pharynx.

The width of the hyoid body correlates most highly with bicondylar breadth of

Table 10. Standardized Canonical Discriminant Function Coefficients and Structure Matrix (MTD, MMH, DPS of Hyoid Body Only, All Three Extant Species, Subadults Only)

\begin{tabular}{lrr} 
MEASURE & \multicolumn{2}{c}{ DISCRIMINANT FUNCTION } \\
& 1 & 2 \\
\hline Standardized canonical discriminant function coefficients & & \\
DPS & 1.724 & -0.548 \\
MMH & -1.289 & -0.443 \\
MTD & 0.153 & 1.378 \\
Structure matrix & & \\
DPS & 0.741 & 0.035 \\
MMH & 0.260 & 0.039 \\
MTD & 0.378 & 0.724 \\
\hline
\end{tabular}

For abbreviations, see Table 1.

Table 11. Classification of Hyoid Bones using Discriminant Function (MTD, MMH, DPS of Hyoid Body Only, All Three Extant Species, Subadults Only; Dikika Hyoid Included as Ungrouped Case)

\begin{tabular}{lcccr} 
SPECIES & \multicolumn{2}{c}{ PREDICTED GROUP MEMBERSHIP } & TOTAL \\
& HUMAN & CHIMPANZEE & GORILLA & \\
\hline Human & 28 & 0 & 0 & 28 \\
Chimpanzee & 0 & 15 & 2 & 17 \\
Gorilla & 0 & 3 & 14 & 17 \\
Dikika (ungrouped) & 0 & 1 & 0 & 1 \\
\hline
\end{tabular}




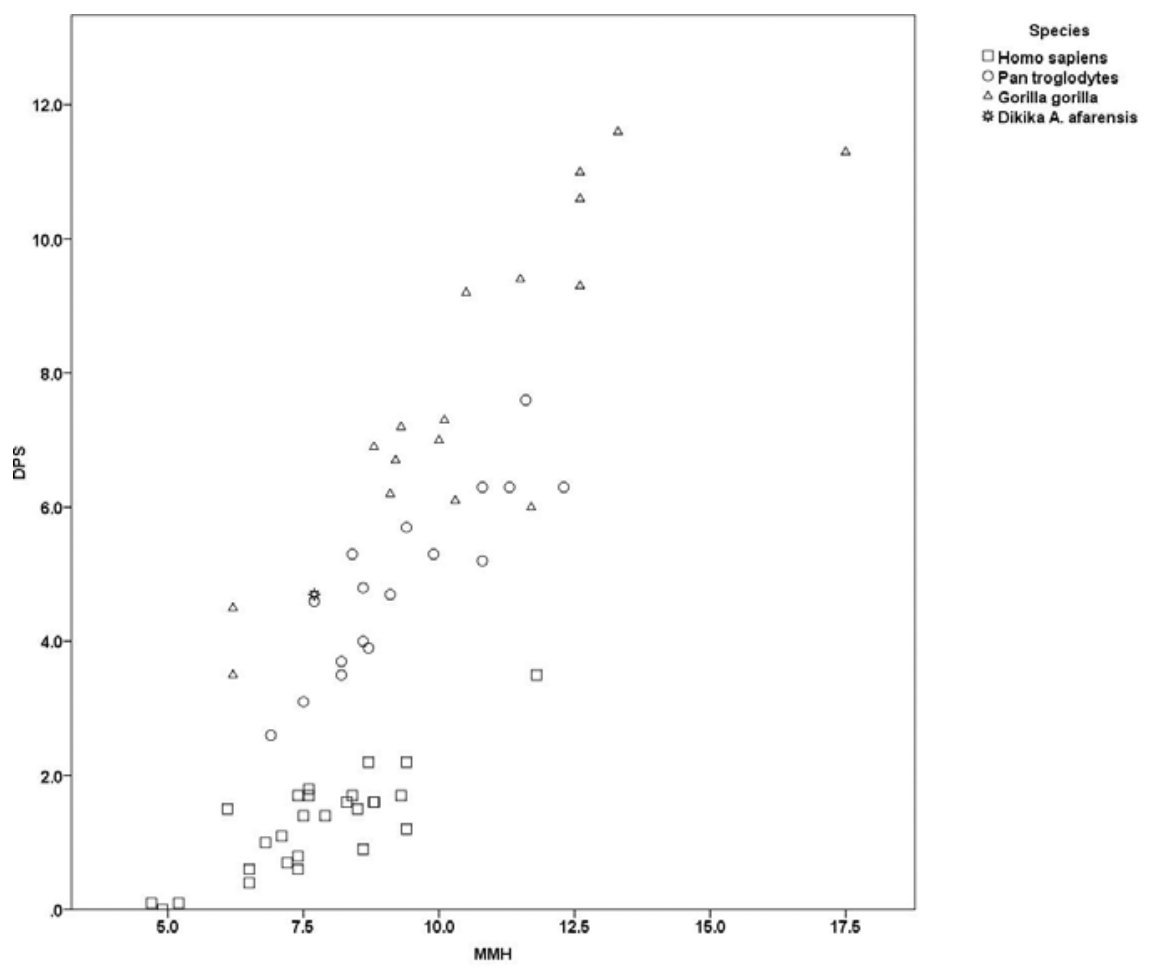

Figure 9a. Scatter plots of values for hyoid body depth (DPS) plotted against height (MMH). (A, top) Subadults of all three extant species, plus the Dikika juvenile A. afarensis.

the mandible (MTD vs. MBB, Pearson's $r=0.59 ; p<0.01$, all three species pooled; Figure 12A) and is next most highly correlated with mandibular bigonial breadth (MTD vs. MGB, Pearson's $r=0.55 ; p<0.01$, all three species pooled; Figure 12B), which must also reflect a size relationship between these closely contiguous structures. In the Kebara Neanderthal, the scaling of maximum bigonial breadth of the mandible to maximum transverse diameter of the hyoid body is consistent with this observed relationship in the extant species (Figure 12B).

\section{Discussion}

Humans and African apes form a distinct clade, within which it is relevant to look for phenotypic evidence of divergent behavioral evolution. Human and African ape hyoid bones have distinct morphologies. The hyoid measurements recorded in this study from a human sample from early modern London reproduce with remarkable consistency the pattern found by Arensburg et al. (1989), in their earlier study of five Holocene human populations from Europe and the Near East (see Table 13). 


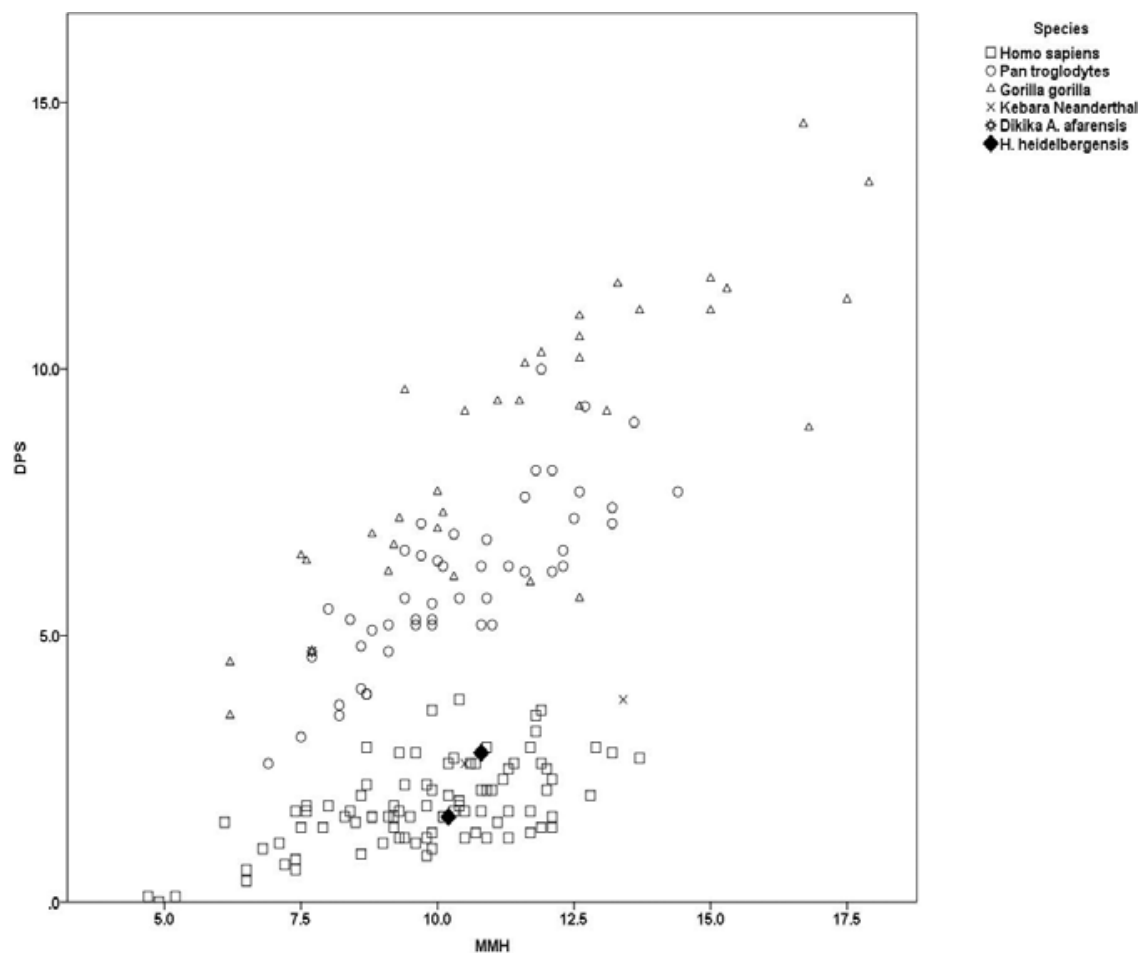

Figure 9b. Subadults and adults of all three extant species, plus the Dikika juvenile A. afarensis, Atapuerca (SH) H. heidelbergensis, and Kebara Neanderthal specimens.

Human hyoids usually have a slightly greater total maximum breadth than total maximum length, and their bodies are relatively shallow anteroposteriorly, although their maximum transverse diameters do not differentiate them from the African apes.

The discriminant function coefficients indicate that the hyoids of the African apes and of humans are principally distinguished by the relative depth of the body (i.e., the presence or absence of the expanded bulla), which reflects the presence or absence of a subhyoid air sac extension (as our chimpanzee virtual dissection clearly illustrates). The discriminant function analysis did not misclassify any adult human hyoids. The adult chimpanzee and gorilla hyoids are more similar, to the extent that a small number of examples from one species were wrongly classified as the other, in the post hoc analysis. The primary difference in the African ape bones is in their total maximum length and in the depth of the body, the gorilla hyoids being on average larger in these dimensions than the chimpanzee examples even after controlling for hyoid body width and height.

We predicted that total maximum length (TML) of the hyoid would covary with anteroposterior length of the basal oropharynx and tongue root, and that total 


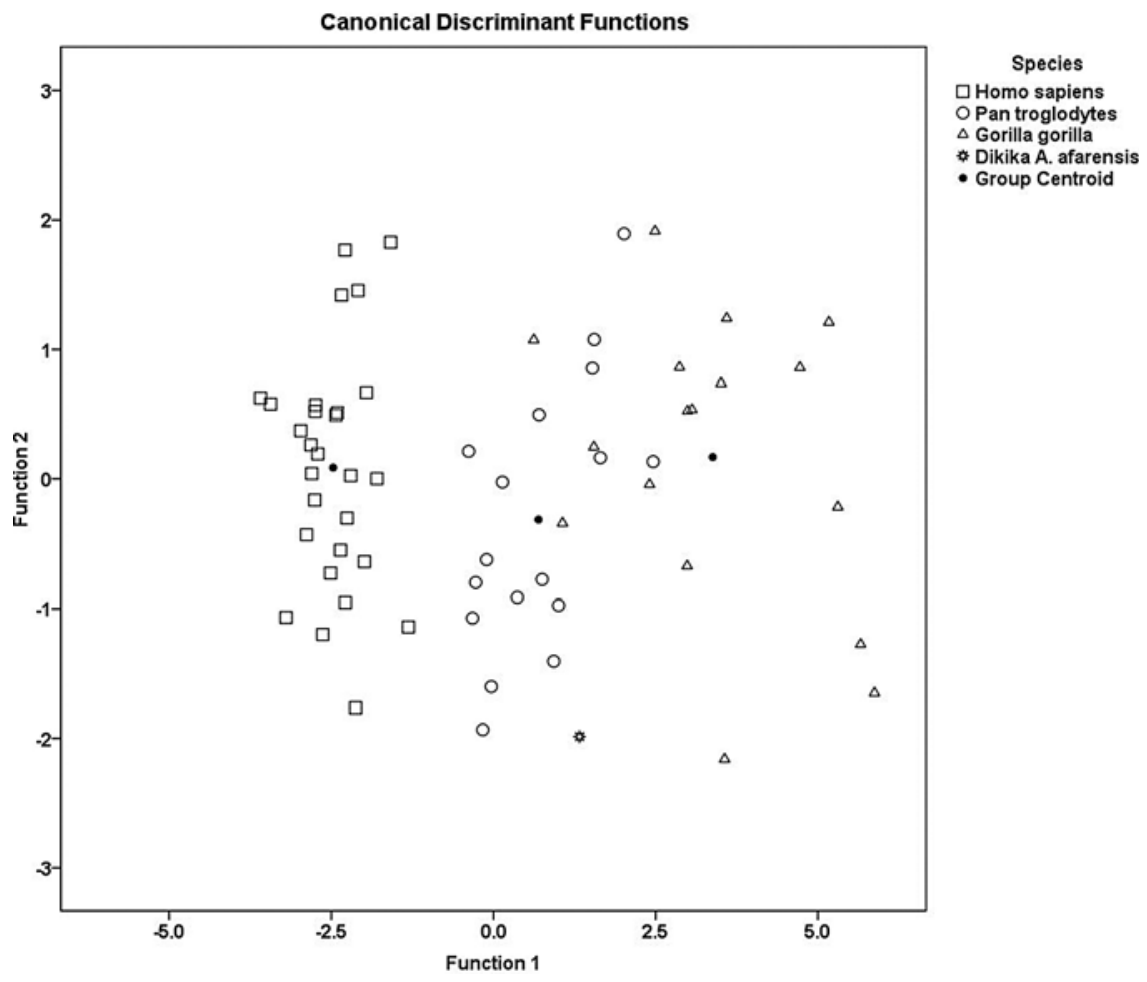

Figure 10. Discriminant function plot for all groups (humans, chimpanzees, and gorillas, subadults only) with the position of the Dikika hyoid also shown, for MTD, MMH, and DPS dimensions of hyoid body only (see Table 9).

maximum breadth (TMB) of the hyoid (distance between the distal greater horns in their anatomical positions) would covary with transverse diameter of the basal oropharynx. Published soft tissue measurements of adult humans are consistent with these expectations. Perrier et al. (1992) found the transverse diameter of the basal oropharynx to be $41 \mathrm{~mm}$ in a cast from a single adult vocal tract, which is in the middle of the range for TMB in our own adult skeletal sample $(40.7 \pm 5.2$ mm., $n=21$ ). The pharyngeal cavity at this level is longer in transverse than in sagittal diameter, and it is the sagittal diameter of the tongue root that makes the additional contribution to TML. Taylor et al. (1996) found the average distance from the superior point of the anterior hyoid body to the posterior wall of the pharynx in the midline to be $28 \mathrm{~mm}$ in females and $35 \mathrm{~mm}$ in males, based on samples of 18-year-olds measured from lateral cephalometric radiographs. This is approximately consistent with our own findings of an overall mean adult TML of $36 \mathrm{~mm}$, with a mean for adult females $(n=17)$ of $34 \mathrm{~mm}$ and a mean for adult males $(n=20)$ of $38 \mathrm{~mm}$. It would be useful in the future to collect more data 
on oral and pharyngeal cavity dimensions in chimpanzees and gorillas, so that species differences in hyoid dimensions can also be correlated more precisely with the dimensions of these soft tissue structures and the relevance inferred for any functional differences in, for example, swallowing movements. In the African apes, the relatively large values found for TML also reflect a third factor-the greater depth and curvature of the hyoid body itself, which is filled by a laryngeal air sac.

Examining the fossil hyoids and comparing them with the modern hominoid samples show that the Dikika A. afarensis hyoid has the expanded bulla found in the African apes associated with retention of the laryngeal air sac with its subhyoid extension (Alemseged et al. 2006). The Kebara Neanderthal specimen and the hyoid body of the juvenile Australopithecus afarensis from Dikika, Ethiopia (Alemseged et al. 2006) are not the only published hyoids from extinct hominins, although they are the best known. Hyoids of extinct hominins were also found at two Spanish sites. In Spain the El Sidron site, dated to about 43 kya, yielded a hyoid body assigned to Neanderthal that is very similar in size and shape to that of modern humans (Rodriguez et al. 2003). The Sima de los Huesos site (also from

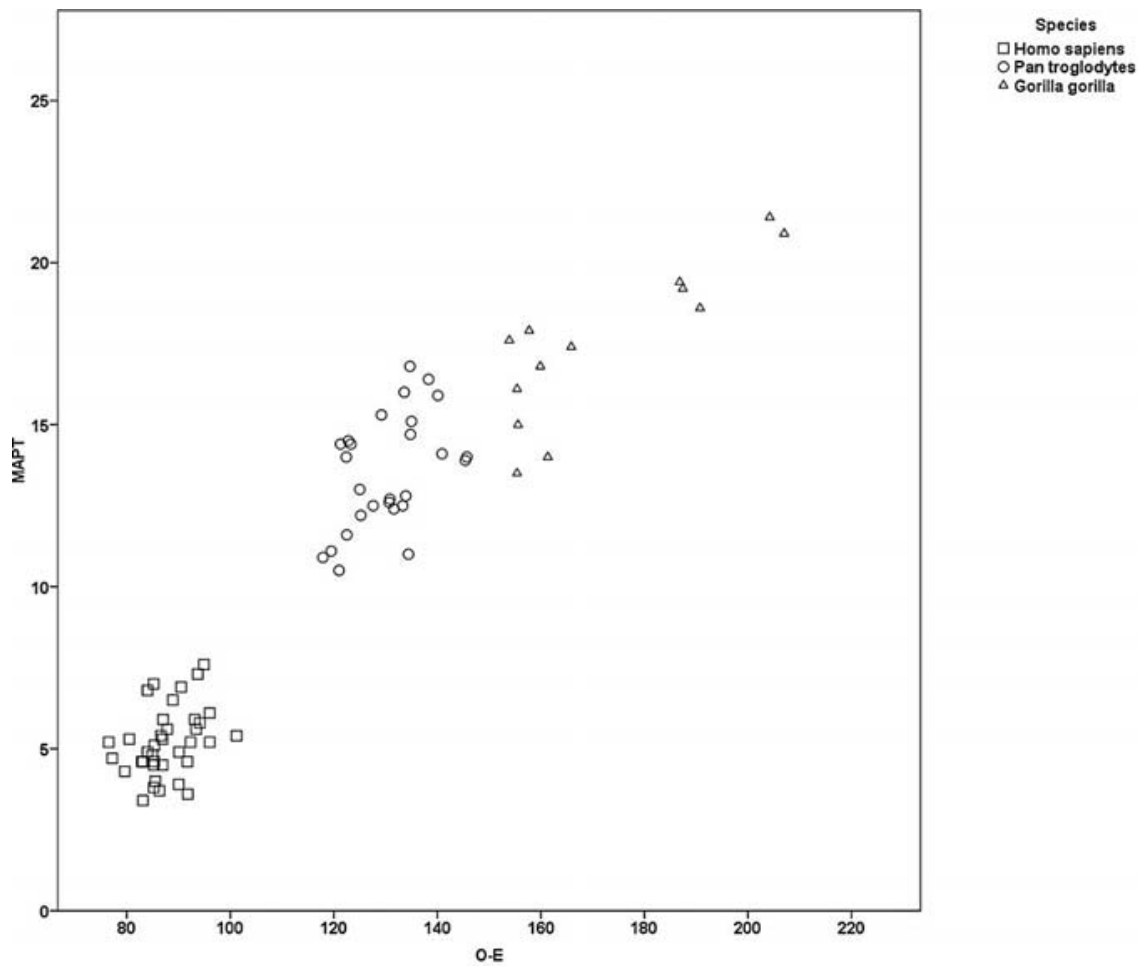

Figure 11. Scaling of maximum anteroposterior thickness (MAPT) of the hyoid body to cranial base length (O-E, orale-endobasion) in adults of the three extant species. 
Table 12. Bivariate Correlations (Adults Only, All Three Extant Species Pooled): Hyoid Dimensions (Rows) and Cranial and Mandibular Dimensions (Columns)

\begin{tabular}{llrrrrrrr} 
MEASURE & & O-E & BIZYGO & C-E & CC-CC & HR & IPB & IPL \\
\hline DPS & $r$ & 0.927 & 0.639 & 0.871 & -0.556 & 0.722 & 0.113 & 0.925 \\
& $p$ & $<0.001$ & $<0.001$ & $<0.001$ & $<0.001$ & $<0.001$ & 0.350 & $<0.001$ \\
& $n$ & 83 & 85 & 94 & 91 & 99 & 71 & 88 \\
\hline LGH & $r$ & 0.716 & 0.621 & 0.686 & -0.289 & 0.622 & 0.248 & 0.670 \\
& $p$ & $<0.001$ & $<0.001$ & $<0.001$ & 0.013 & $<0.001$ & 0.061 & $<0.001$ \\
& $n$ & 66 & 68 & 74 & 73 & 76 & 58 & 68 \\
\hline MAPT & $r$ & 0.952 & 0.620 & 0.889 & -0.599 & 0.713 & 0.141 & 0.943 \\
& $p$ & $<0.001$ & $<0.001$ & $<0.001$ & $<0.001$ & $<0.001$ & 0.240 & $<0.001$ \\
& $n$ & 83 & 85 & 94 & 91 & 99 & 71 & 88 \\
\hline MMH & $r$ & 0.386 & 0.487 & 0.368 & 0.048 & 0.410 & 0.082 & 0.354 \\
& $p$ & $<0.001$ & $<0.001$ & $<0.001$ & 0.651 & $<0.001$ & 0.494 & 0.001 \\
& $n$ & 84 & 86 & 95 & 92 & 100 & 72 & 89 \\
\hline MTD & $r$ & 0.384 & 0.479 & 0.275 & 0.175 & 0.378 & 0.368 & 0.292 \\
& $p$ & $<0.001$ & $<0.001$ & 0.007 & 0.097 & $<0.001$ & 0.002 & 0.006 \\
& $n$ & 83 & 85 & 94 & 91 & 98 & 70 & 87 \\
\hline TMB & $r$ & -0.531 & -0.130 & -0.478 & 0.713 & -0.293 & -0.368 & -0.603 \\
& $p$ & 0.013 & 0.586 & 0.016 & $<0.001$ & 0.146 & 0.160 & 0.003 \\
& $n$ & 21 & 20 & 25 & 24 & 26 & 16 & 22 \\
\hline TML & $r$ & 0.914 & 0.728 & 0.855 & -0.390 & 0.850 & 0.202 & 0.891 \\
& $p$ & $<0.001$ & $<0.001$ & $<0.001$ & 0.020 & $<0.001$ & 0.355 & $<0.001$ \\
& $n$ & 30 & 32 & 37 & 35 & 39 & 23 & 31 \\
\hline WGH & $r$ & 0.600 & 0.700 & 0.568 & 0.020 & 0.672 & 0.376 & 0.527 \\
& $p$ & $<0.001$ & $<0.001$ & $<0.001$ & 0.860 & $<0.001$ & 0.002 & $<0.001$ \\
& $n$ & 73 & 75 & 81 & 80 & 84 & 63 & 75 \\
\hline & & & & & & & &
\end{tabular}

For abbreviations, see Table 1. Significance levels: $p<0.001$ for $\alpha=0.05$ after applying Bonferroni's correction for multiple comparisons ( $n=56$ tests).

Spain) yielded two hyoid bodies, assigned late subadult or adult developmental ages (Martinez et al. 2008). These two hyoids are of great interest because they are attributed to pre-Neanderthal archaic Homo (Homo heidelbergensis) and date to approximately $530 \mathrm{kya}$. The absence of an expanded bulla in these hyoid bodies of humans, Neanderthals, and Homo heidelbergensis suggests that they shared the derived feature of an absence of laryngeal air sacs. There is no evidence, nor to our knowledge any plausible functional reason to expect, that later hominins passed through an orangutan-like stage with a large air sac that did not impinge on the hyoid body. Such a suggestion would lack parsimony. The loss of the air sac system can therefore be dated to no later than the middle Pleistocene.

Our study has focused on comparative hyoid bone morphology in African apes and humans and its implications for the presence or absence of an air sac 


\begin{tabular}{rrrrrrrrr} 
MBB & MGB & ML & S.HT & SM-SM & TP-PA & TP-TP & U.FACE \\
\hline 0.400 & 0.323 & 0.880 & 0.895 & -0.380 & 0.864 & 0.720 & 0.848 \\
$<0.001$ & 0.002 & $<0.001$ & $<0.001$ & $<0.001$ & $<0.001$ & $<0.001$ & $<0.001$ \\
91 & 91 & 90 & 85 & 91 & 92 & 93 & 85 \\
\hline 0.511 & 0.440 & 0.735 & 0.691 & -0.136 & 0.693 & 0.646 & 0.696 \\
$<0.001$ & $<0.001$ & $<0.001$ & $<0.001$ & 0.250 & $<0.001$ & $<0.001$ & $<0.001$ \\
73 & 74 & 73 & 69 & 73 & 74 & 74 & 65 \\
\hline 0.367 & 0.305 & 0.917 & 0.916 & -0.463 & 0.868 & 0.712 & 0.884 \\
$<0.001$ & 0.003 & $<0.001$ & $<0.001$ & $<0.001$ & $<0.001$ & $<0.001$ & $<0.001$ \\
91 & 91 & 90 & 85 & 91 & 92 & 93 & 85 \\
\hline 0.511 & 0.454 & 0.370 & 0.453 & 0.172 & 0.449 & 0.526 & 0.388 \\
$<0.001$ & $<0.001$ & $<0.001$ & $<0.001$ & 0.102 & $<0.001$ & $<0.001$ & $<0.001$ \\
92 & 92 & 91 & 86 & 92 & 93 & 94 & 86 \\
\hline 0.584 & 0.554 & 0.336 & 0.346 & 0.210 & 0.412 & 0.499 & 0.411 \\
$<0.001$ & $<0.001$ & 0.001 & 0.001 & 0.045 & $<0.001$ & $<0.001$ & $<0.001$ \\
91 & 91 & 90 & 84 & 91 & 92 & 93 & 84 \\
\hline-0.040 & -0.022 & -0.548 & -0.488 & 0.627 & -0.405 & -0.156 & -0.440 \\
0.854 & 0.920 & 0.007 & 0.034 & 0.001 & 0.044 & 0.467 & 0.046 \\
24 & 24 & 23 & 19 & 24 & 25 & 24 & 21 \\
\hline 0.615 & 0.484 & 0.900 & 0.880 & -0.175 & 0.901 & 0.812 & 0.887 \\
$<0.001$ & 0.002 & $<0.001$ & $<0.001$ & 0.315 & $<0.001$ & $<0.001$ & $<0.001$ \\
37 & 37 & 36 & 31 & 35 & 36 & 36 & 29 \\
\hline 0.678 & 0.663 & 0.542 & 0.577 & 0.228 & 0.641 & 0.709 & 0.620 \\
$<0.001$ & $<0.001$ & $<0.001$ & $<0.001$ & 0.043 & $<0.001$ & $<0.001$ & $<0.001$ \\
79 & 80 & 79 & 75 & 79 & 81 & 81 & 71 \\
\hline & & & & & & &
\end{tabular}

system. If the presence of an air sac system hinders the production of easily perceptible contrasts in basic speech sounds, and its absence in humans reflects selection against that hindrance (as proposed, based on his experimental and modeling work, by de Boer 2009, 2012), then the emergence of human-like speech can also therefore be dated to no later than the middle Pleistocene. Our comparative analysis was, by its nature as a dry bone study, unable to identify any association between the shape or size of the hyoid bone and its position in relation to the mandible; our study therefore sheds no new light on the vexing question of the lengths of the vertical and horizontal portions of the supralaryngeal vocal tract in fossil hominins (see Fitch 2009). However, elsewhere we have explored the reconstruction of the Neanderthal vocal tract using three-dimensional shape analyses and software articulatory models of vowel production, with hyoid position 


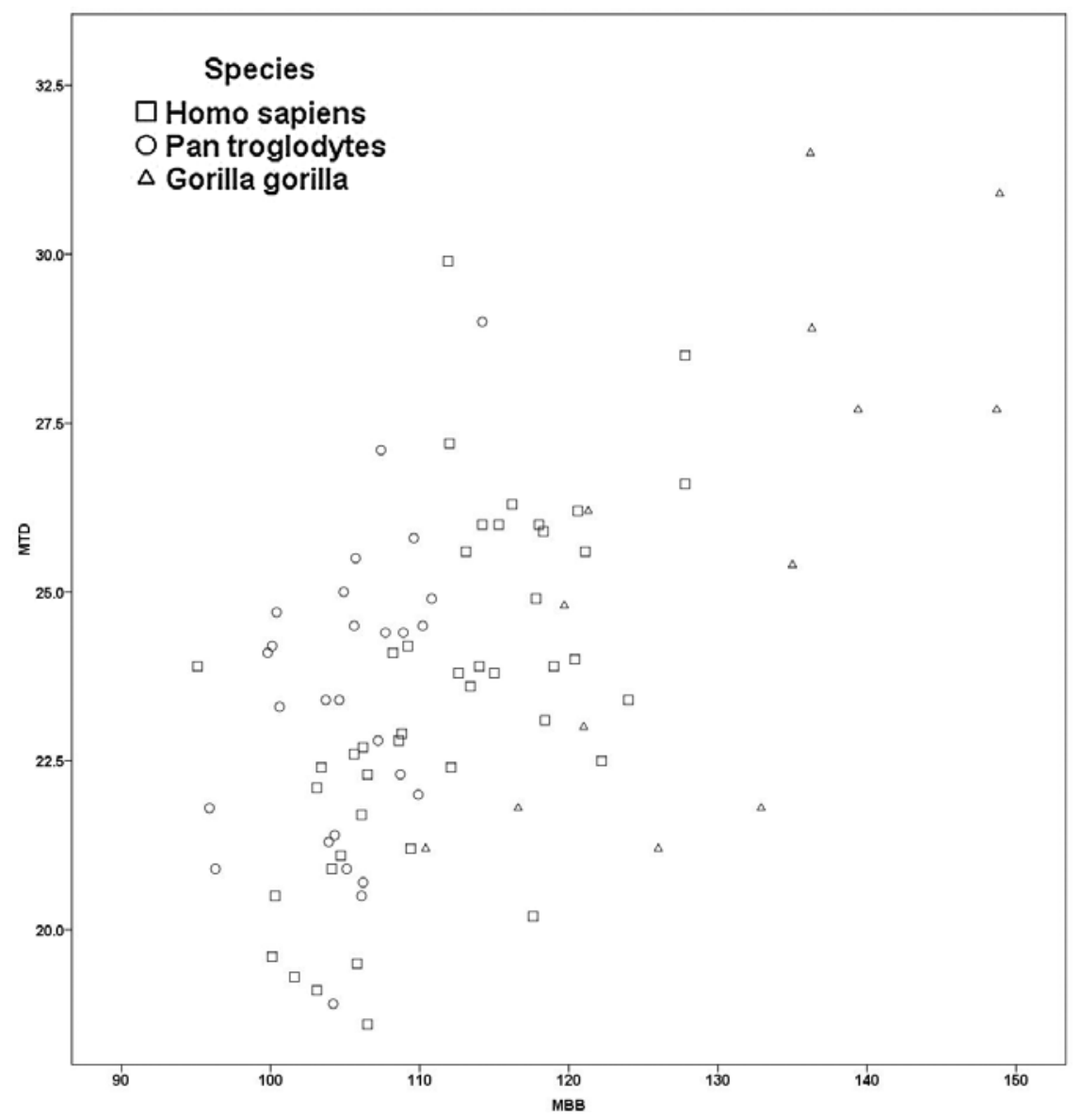

Figure 12a. Scaling of maximum transverse diameter (MTD) of the hyoid body to mandibular bicondylar breadth (MBB) in adults of the three extant species.

predicted by extrapolation from a reference sample of head-and-neck scans of adult humans (Barney et al. 2012); similarly to Boë et al. (2002, 2011), we found that the reconstructed Neanderthal tract has properties comparable to those of humans, although the necessity of estimating fossil hominin soft tissue relationships from an extant reference species limits independent validation of the modeling assumptions. The presence in Neanderthals of the human variant of the FOXP2 gene (Krause et al. 2007; Burbano et al. 2010), the possible skeletal evidence of adaptations for "speech breathing" (Maclarnon and Hewitt 1999, 2004), the skeletal evidence for $H$. heidelbergensis and Neanderthal right-handedness (e.g., Steele and Uomini 2009; Frayer et al. 2012; Volpato et al. 2012), and the presence in Neanderthals of the human pattern of cerebral petalias (e.g., Balzeau et al.2012) provide additional independent supporting evidence for a capacity for speech in these fossil hominins. 


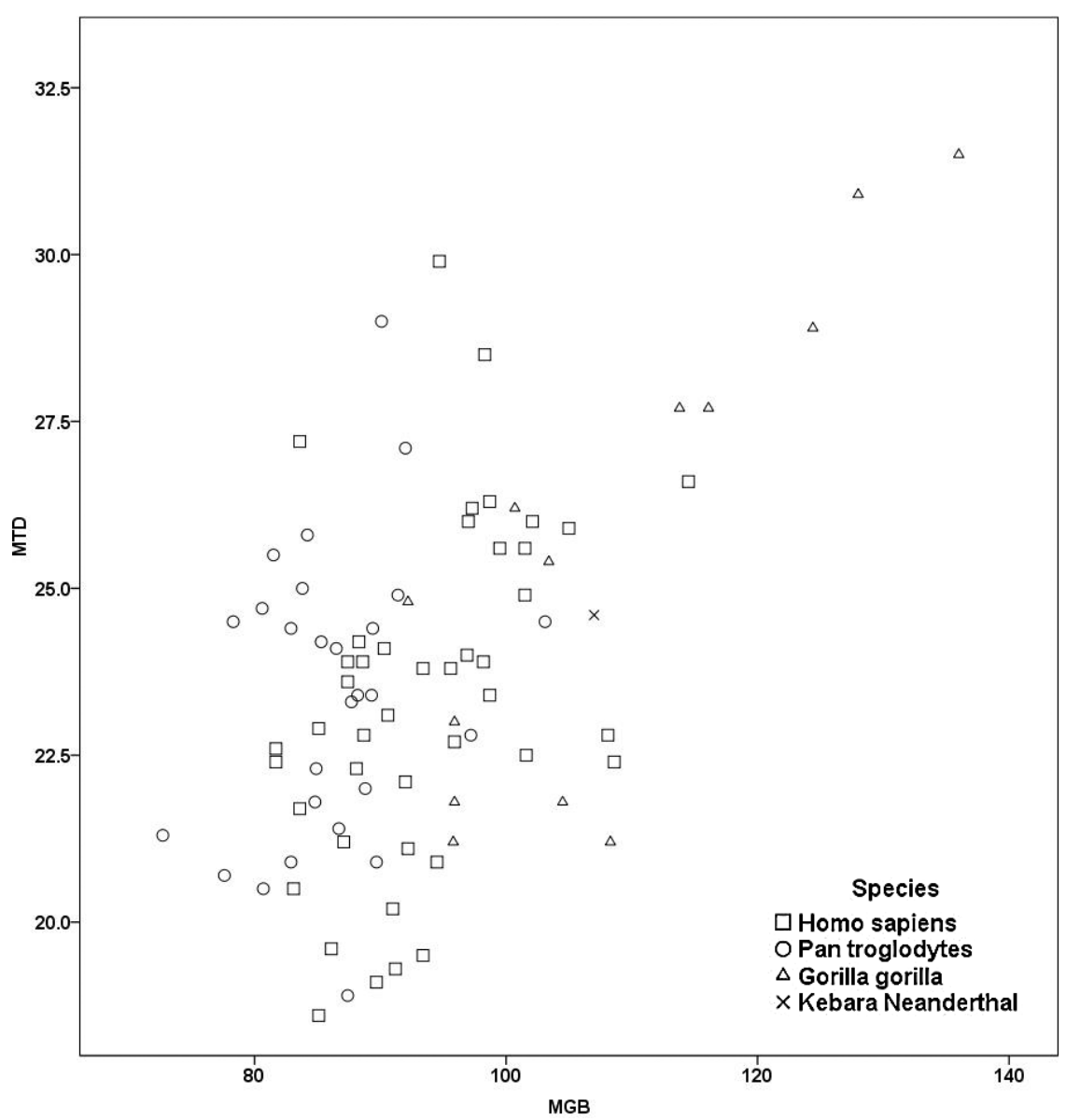

Figure 12b. Scaling of MTD of the hyoid body to mandibular bigonial breadth (MGB) in adults of the three extant species, with values also shown for the Kebara Neanderthal. MGB for Kebara taken from Tillier (1991).

Table 13. Comparison of Human Adult Hyoid Data (mm, Mean \pm SD) Recorded in This Study and by Arensburg et al. (1989) for the Dimensions Reported in Both Studies

\begin{tabular}{lcccccc} 
HUMAN GROUP & TML & TMB & MTD & MMH & APT & DPS \\
\hline This study & $36.0 \pm 4.1$ & $40.7 \pm 5.2$ & $23.4 \pm 2.5$ & $10.6 \pm 1.2$ & $5.1 \pm 1.0$ & $2.0 \pm 0.7$ \\
$n$ & 37 & 21 & 62 & 63 & 63 & 63 \\
Arensburg et al. & $36.65 \pm 3.2$ & $38.97 \pm 2.7$ & $21.35 \pm 2.66$ & $10.66 \pm 1.27$ & $5.13 \pm 0.97$ & $2.03 \pm 0.59$ \\
$(1989)$ & 11 & 12 & 48 & 67 & 65 & 66 \\
$n$ & & & &
\end{tabular}

For abbreviations, see Table 1. 
Acknowledgments It is a special pleasure to acknowledge the editorial feedback and guidance of Franz Manni and Nancy Wise. We thank Christophe Zollikofer, Marcia Ponce de Leon, Jürg Hodler, and Frank Rühli for assistance in obtaining CT scans of a chimpanzee from the collections of the Anthropological Institute, University of Zurich. We thank Robert Kruszynski and the staff of the British Museum (Natural History) and Simon Mays of English Heritage for access to the human material, and Malcolm Harman and the staff of the Powell-Cotton Museum for access to the African ape material. We thank Manu Davies for checking and editing the digital transcription of the database. We thank Fred Spoor for consultation on details of the version of the comparative data set used by Alemseged et al. (2006). We thank Leslie Aiello, Anna Barney, William Kimbel, Daniel Lieberman, Fred Spoor, and three anonymous reviewers for their comments, which have greatly improved the present version. Any remaining errors remain our own. M.C. acknowledges grant support from the British Academy Social Brain project. J.S. and S.M. acknowledge grant support from the HANDTOMOUTH Project (EC FP6 Contract No. 29065; NEST2004-PATH-HUMAN) and from the AHRC Centre for the Evolution of Cultural Diversity (University College London).

Received 18 June 2013; revision accepted for publication 30 July 2013.

\section{Literature Cited}

Aiello, L., and C. Dean. 1990. An Introduction to Human Evolutionary Anatomy. San Diego: Academic Press.

Alemseged, Z., F. Spoor, W. H. Kimbel et al. 2006. A juvenile early hominin skeleton from Dikika, Ethiopia. Nature 443:296-301.

Arensburg, B., L. A. Schepartz, A. M. Tillier et al. 1990. A reappraisal of the anatomical basis for speech in Middle Palaeolithic hominids. Am. J. Phys. Anthropol. 83:137-156.

Arensburg, B., A. M. Tillier, H. Duday et al. 1989. A Middle Palaeolithic human hyoid bone. Nature 338:758-760.

Avril, C. 1963. Kehlkopf und Kehlsack des Schimpansen, Pan troglodytes (Blumenbach 1799). Gegenbaurs Morphol. Jahrb. 105:74-129.

Balzeau, A., R. L. Holloway, and D. Grimaud-Hervé. 2012. Variations and asymmetries in regional brain surface in the genus Homo. J. Hum. Evol. 62:696-706.

Barney, A., S. Martelli, A. Serrurier et al. 2012. Articulatory capacity of Neanderthals, a very recent and human-like fossil hominin. Philos. Trans. R. Soc. Lond. B. Biol. Sci. 367:88-102.

Boë, L. J., J. Granat, J. L. Heim et al. 2011. Ability of reconstituted fossil vocal tracts to produce speech: Phylogenetic and ontogenetic considerations. In 9th International Seminar on Speech Production 2011: ISSP, Montreal, Canada, June 20-23 2011, 313-320. www.issp2011.uqam. ca/upload/files/proceedings.pdf.

Boë, L. J., J. L. Heim, K. Honda et al. 2002. The potential Neandertal vowel space was as large as that of modern humans. J. Phonet. 30:465-484.

Brandes R. 1932. Über den Kehlkopf des Orang-Utan in verschiedenen Altersstadien mit besonderer Berücksichtigung der Kehlsackfrage. Gegenbaurs Morphol. Jahrb. 69:1-61.

Burbano, H. A., E. Hodges, R. E. Green et al. 2010. Targeted investigation of the Neandertal genome by array-based sequence capture. Science 328:723-725.

Clegg, M. 2001. The comparative anatomy and evolution of the human vocal tract. Ph.D. diss., University of London. 
de Boer, B. 2009. Acoustic analysis of primate air sacs and their effect on vocalization. J. Acoust. Soc. Am. 126:3,329-3,343

de Boer, B. 2012. Loss of air sacs improved hominin speech abilities J. Hum. Evol. 62:1-6.

Dodds, W. J., E. T. Stewart, and J. A. Logemann. 1990. Physiology and radiology of the normal oral and pharyngeal phases of swallowing. Am. J. Roentgenol. 154:953-963.

Falk, D. 1975. Comparative anatomy of the larynx in man and the chimpanzee: Implications for language in Neanderthal. Am. J. Phys. Anthropol. 43:123-132.

Fick, R. 1895. Vergleichend anatomische Studien an einem erwachsenen Orang-Utang. Arch. Anat. Physiol. 1:1-100.

Fitch, W. T. 2000a. The evolution of speech: A comparative review. Trends Cogn. Sci. 4:258-267.

Fitch, W. T. 2000b. The phonetic potential of nonhuman vocal tracts: Comparative cineradiographic observations of vocalizing animals. Phonetica 57:205-218.

Fitch, W. T. 2009. Fossil cues to the evolution of speech. In The Cradle of Language, R. P. Botha and C. Knight, eds. Oxford: Oxford University Press, 112-134.

Fitch, W. T., and M. D. Hauser. 1995. Vocal production in nonhuman primates: Acoustics, physiology, and functional constraints on "honest" advertisement. Am. J. Primatol. 37:191-219.

Fitch, W. T., and D. Reby. 2001. The descended larynx is not uniquely human. Proc. R. Soc. Lond. B Biol. Sci. 268:1,669-1,675.

Frayer, D. W., M. Lozano, J. M. Bermudez de Castro et al. 2012. More than 500,000 years of righthandedness in Europe. Laterality Asymm. Body Brain Cognit. 17:51-69.

Hewitt, G., A. MacLarnon, and K. E. Jones. 2002. The functions of laryngeal air sac in primates: A new hypothesis. Folia Primatol. 73:70-94.

Hilloowala, R. A. 1975. Comparative anatomical study of hyoid apparatus in selected primates. Am. J. Anat. 142:367-384.

Hilloowala, R. A., and N. J. Lass. 1978. Spectrographic analysis of laryngeal air sac resonance in rhesus monkey. Am. J. Phys. Anthropol. 49:129-131.

Kelemen, G. 1963. Comparative anatomy and performance of the vocal organ in vertebrates. In Acoustic Behaviour of Animals, R.-G. Busnel, ed. New York: Elsevier, 489-521.

Krause, J., C. Lalueza-Fox, L. Orlando et al. 2007. The derived FOXP2 variant of modern humans was shared with Neandertals. Curr. Biol. 17:1,908-1,912.

Liem, K. F., W. E. Bemis, F. W. Walker et al. 2001. Discriminant Functional Anatomy of the Vertebrates. Fort Worth, TX: Harcourt.

MacLarnon, A., and G. Hewitt. 1999. The evolution of human speech: The role of enhanced breathing control. Am. J. Phys. Anthropol. 109:341-363.

MacLarnon, A. M., and G. P. Hewitt. 2004. Increased breathing control: Another factor in the evolution of human language. Evol. Anthropol. 13:181-197.

Martinez, I., J. L. Arsuaga, R. Quam et al. 2008. Human hyoid bones from the middle Pleistocene site of the Sima de los Huesos (Sierra de Atapuerca, Spain). J. Hum. Evol. 54:118-124.

Meikle, M. C. 2002. Craniofacial Development, Growth and Evolution. Bressingham, UK: Bateson.

Miller, K. W. P., P. L. Walker, and R. L. O’Halloran. 1998. Age and sex-related variation in hyoid bone morphology. J. Forensic Sci. 43:1138-1143.

Miller, R. A. 1941. The laryngeal sacs of an infant and an adult gorilla. Am. J. Anat. 69:1-17.

Negus, V. E. 1949. The Comparative Anatomy and Physiology of the Larynx. London: Heinemann.

Nemai, J. 1920. Das Stimmorgan der Primaten. Z. Anat. Entwicklungsgesch. 59:257-292.

Nemai, J. 1926. Das Stimmorgan der Primaten. Z. Anat. Entwicklungsgesch. 81:657-672.

Nemai, J., and G. Kelemen. 1929. Das Stimmorgan des Orang-Utan. Z. Anat. Entwicklungsgesch. 88:697-709.

Nishimura, T., A. Mikami, J. Suzuki et al. 2007. Development of the laryngeal air sac in chimpanzees. Int. J. Primatol. 28:483-492.

O'Halloran, R. L., and J. K. Lundy. 1987. Age and ossification of the hyoid bone: forensic implications. J. Forensic Sci. 32:1655-1659. 
Perrier, P., L.-J. Boe, and R. Sock. 1992. Vocal tract area function estimation from midsagittal dimensions with CT scans and a vocal tract cast: Modeling the transition with two sets of coefficients. J. Speech Hear. Res. 35:53-67.

Riede, T., I. T. Tokuda, J. B. Munger et al. 2008. Mammalian laryngeal air sacs add variability to the vocal tract impedance: Physical and computational modeling. J. Acoust. Soc. Am. 124:634-647.

Rodriguez, L., J. E. Egocheaga, and L. L. Cabo. 2003. Breve nota sobre el hioides Neandertalense de Sidron (Pilona, Asturias). In Antropologia y Diversidad, vol. 1, M. P. Aluja, A. Malgosa, and R. N. Nogués, eds. Barcelona: Edicions Bella-terra, 484-493.

Sawada, M. 1999. LPC Freeware: Statistics. Model II Regression: Performs Geometric Mean Regression in Excel '97. www.lpc.uottawa.ca/data/scripts/index.html.

Schön, M. 1971. The anatomy of the resonating mechanism in howling monkeys. Fol. Primatol. 15:117-132.

Schön Ybarra, M. 1995. A comparative approach to the nonhuman primate vocal tract: Implications for sound production. In Current Topics in Primate Vocal Communication, E. Zimmerman and J. D. Newman, eds. New York: Plenum Press, 185-198.

Senecail, B. 1979. L'Os Hyoide: Introduction Anatomique a l'Etude de Certains Mechanisms de la Phonation. Paris: Memoires du Laboratorie d'Anatomie et de la Faculte de Medecine de Paris.

Sonntag, C. F. 1924. The Morphology and Evolution of the Apes and Man. London: John Bale, Sons and Danielsson.

SPSS Inc. 2005. SPSS 14.0 for Windows. Chicago, IL: SPSS Inc.

Steele, J., and N. Uomini. 2009. Can the archaeology of manual specialization tell us anything about language evolution? A survey of the state of play. Camb. Archaeol. J. 19:97-110.

Swindler, D. R., and C. D. Wood. 1973. An Atlas of Primate Gross Anatomy. Seattle: University of Washington Press.

Taylor, M., M. G. Hans, K. P. Strohl et al. 1996. Soft tissue growth of the oropharynx. Angle Orthodont. 66:393-400.

Tillier, A.-M. 1991. La mandibule et les dents. In Le squelette Moustérien de Kébara 2, O. Bar Yosef and B. Vandermeersch, eds. Paris: Centre national de la recherche scientifique, 97-111.

Volpato, V., R. Macchiarelli, D. Guatelli-Steinberg et al. 2012. Hand to mouth in a Neandertal: Righthandedness in Regourdou 1. PloS ONE 7:e43949. 